\title{
1 A collective modulatory basis for multisensory integration in C. elegans
}

3 Gareth Harris ${ }^{1,2,}{ }^{*}$ Taihong Wu${ }^{1}$, Gaia Linfield ${ }^{1}$, Myung-Kyu Choi ${ }^{1}$, He Liu ${ }^{1}$ and Yun Zhang ${ }^{1,}{ }^{*}$

5 1. Department of Organismic and Evolutionary Biology, Center for Brain Sciences, Harvard

6 University, Cambridge, MA 02138, USA.

7 2. Current address: California State University Channel Islands, 1 University Dr., Camarillo, CA

893012, USA.

9

10

$11 *$ Corresponding authors

12 E-mail: gazalad2@hotmail.com or yzhang@oeb.harvard.edu 


\section{Abstract}

16 In the natural environment, animals often encounter multiple sensory cues that are

17 simultaneously present. The nervous system integrates the relevant sensory information to

18 generate behavioral responses that have adaptive values. However, the signal transduction

19 pathways and the molecules that regulate integrated behavioral response to multiple sensory

20 cues are not well defined. Here, we characterize a collective modulatory basis for a behavioral

21 decision in $C$. elegans when the animal is presented with an attractive food source together with

22 a repulsive odorant. We show that distributed neuronal components in the worm nervous system and several neuromodulators orchestrate the decision-making process, suggesting that various states and contexts may modulate the multisensory integration. Among these modulators, we identify a new function of a conserved TGF- $\beta$ pathway that regulates the integrated decision by inhibiting the signaling from a set of central neurons. Interestingly, we find

27 that a common set of modulators, including the TGF- $\beta$ pathway, regulate the integrated response to the pairing of different foods and repellents. Together, our results provide insights into the modulatory signals regulating multisensory integration and reveal potential mechanistic basis for the complex pathology underlying defects in multisensory processing shared by

31 common neurological diseases.

\section{Author Summary}

34 The present study characterizes the modulation of a behavioral decision in C. elegans when the worm is presented with a food lawn that is paired with a repulsive smell. We show that multiple sensory neurons and interneurons play roles in making the decision. We also identify several modulatory molecules that are essential for the integrated decision when the animal faces a choice between the cues of opposing valence. We further show that many of these factors, which often represent different states and contexts, are common for behavioral decisions that 
bioRxiv preprint doi: https://doi.org/10.1101/424135; this version posted September 21, 2018. The copyright holder for this preprint (which was not certified by peer review) is the author/funder, who has granted bioRxiv a license to display the preprint in perpetuity. It is made available under aCC-BY 4.0 International license.

40 integrate sensory information from different types of foods and repellents. Overall, our results

41 reveal a collective molecular and cellular basis for integration of simultaneously present

42 attractive and repulsive cues to fine-tune decision-making. 


\section{Introduction}

44 An environment is often represented by numerous sensory cues. For example, a tainted food

45 source can produce both attractive and repulsive odorants. In order to better survive, an animal

46 often needs to detect and process simultaneously present sensory cues to make a behavioral

47 decision [1-8]. Because integrating multiple sensory cues generates a more accurate evaluation

48 of the environment, it provides important adaptive values. Multisensory integration is widely

49 observed in both the vertebrate and invertebrate animals. Previous studies using behavioral and

50 psychophysical approaches show that humans and other organisms can integrate an array of

51 sensory stimuli to generate decisions in every-day life [9-11]. One common characteristic of

multisensory behavioral responses and decision-making processes is their ability to be

modulated by various internal states and contexts, including arousal, sleepiness versus

Parkinson's disease, bipolar disorder, depression, schizophrenia, and gambling behaviors,

share deficits associated with sensory processing or decision-making when encountering

multiple sensory stimuli that evoke certain behavioral choices under normal conditions [15-21].

61 Together, these studies reveal multisensory integration as a common neuronal and behavioral

62 process modulated by multiple contexts across the animal kingdom and highlight the importance

63 of understanding the underlying mechanisms in normal as well as disease states.

65 Despite the importance of multisensory integration in animal behavior, our understanding of the

66 underlying signaling mechanisms remains preliminary. The nematode C. elegans provides an

67 opportunity to address the question. C. elegans feeds on bacteria. A bacterial lawn provides 
various types of sensory information, including olfactory, gustatory, mechanical, and gaseous cues. The small nervous system (302 neurons) of C. elegans generates sensorimotor responses to these modalities [22-33] and many of the responses can be shaped by external and internal contexts that modulate neural activities [4, 34-38]. The C. elegans genome encodes the homologues of about $50 \%$ of the molecules expressed in the mammalian brains [39], which in combination with a well-defined wiring diagram of the nervous system [40] allows characterizing of the molecular and circuit basis for multisensory integration during decision-

75 making.

Here, we show that $C$. elegans integrates the information from an attractive food lawn and a simultaneously present repellent to generate a decision on leaving. We show that the decision to leave the lawn depends on the attractiveness of the lawn and the concentration of the repellent. We identify specific neurons and a collection of modulatory molecules that promote or suppress the food-repellant integration underlying the lawn-leaving decision. We further demonstrate that the battery of modulatory molecules and neurons act as common modulators to regulate integrated decisions on different foods paired with different repellants. These findings identify conserved neuronal signals that modulate multisensory processing during decision-making and reveal a collective modulatory basis for multisensory integration.

\section{Results}

\section{C. elegans integrates multiple sensory cues to generate a behavioral decision}

89 To establish a behavioral assay for multisensory integration in C. elegans, we presented a

90 repulsive odorant, 2-nonanone, to the animals on a small lawn of the E. coli strain OP50 (Figure

$911 \mathrm{~A}$ and Experimental Procedures) and assessed the decision of the animals to stay on or leave

92 the lawn over time. Because the OP50 lawn serves as a food source for the worm, under the 
standard condition $C$. elegans stays on the lawn and leaves only at a low frequency $[41,42]$. Meanwhile, 2-nonanone strongly repels C. elegans at concentrations ranging from $10 \%$ to $100 \%$. The olfactory sensory neuron AWB detects and mediates the avoidance of 2-nonanone [43-45]. We first presented a drop of 10\% 2-nonanone close to the edge of an OP50 lawn, on which 15 - 25 young adults acclimatized for one hour (Figure 1A). We found that within a few minutes the animals migrated to the side of the bacterial lawn away from 2-nonanone, stayed on the edge of the lawn before dispersing throughout the lawn without leaving (Figure 1B). This result indicates that $C$. elegans is able to detect and avoid 10\% 2-nonanone even on the food lawn, but the repulsion is not strong enough to suppress the retention of the worm by the food lawn. In contrast, when we presented a drop of higher concentration of 2-nonanone to the worms in the same configuration, the worms migrated to the side of the lawn, started to leave the food lawn in a few minutes, and continued to migrate to the edge of the plate away from the repellent within the one-hour time window of the assay (Figure 1B, 1C and S9 Movie). The foodleaving behavior was robustly evoked with 100\% 2-nonanone (Figure 1B-1E), under which condition a significant number of worms already left the lawn after 2-nonanone was presented to the worms for 15 minutes (Figure 1C). In addition, it took a similar amount of time for the worms to reach the edge of the lawn that was paired with either $10 \%$ or $100 \%$ 2-nonanone (Figure 1D). These results show that $C$. elegans integrates the attraction of a food lawn with the repulsion of 2-nonanone to generate a behavioral decision and that increasing concentration of 2-nonanone enhances lawn leaving (Figure 1B and 1C). These findings are consistent with the general rule that governs multisensory integration, where increasing the reliability of a sensory cue, such as increasing the concentration of 2-nonanone, strengthens the weight of the cue in integration [46]. To characterize the regulatory mechanisms underlying multisensory integration, we used $100 \% 2$-nonanone as the repellent for the rest of the study unless otherwise described. We

17 quantified the percentage of the worm outside the OP50 lawn 15 minutes after the assay began, 18 because it was an early time point when wild type started to show a robust leaving decision. 


\section{Sensory neurons that regulate multisensory integration}

121 To characterize how the nervous system regulates the integrated response to the attractive

122 OP50 lawn and the repulsive odorant 2-nonanone, we first probed the amphidal sensory

123 neurons AWB, which mediate avoidance of 2-nonanone via the function of the cGMP-gated

124 channel subunit tax-2 [43]. Exposure to 2-nonanone suppresses the intracellular calcium

125 transients of AWB $[44,45]$. Consistently, we found that the transgenic animals that selectively

126 expressed a hyperactive form of an amiloride-sensitive sodium channel MEC-4 that generated

127 necrosis of AWB $[43,47]$ did not leave the OP50 lawn when 2-nonanone was present (Figure

$1282 \mathrm{2}$ ) and that many of the worms remained diffusely distributed on the food lawn by the end of

129 the assay. These transgenic animals were defective in avoiding 2-nonanone in the standard

130 chemotaxis assay (S1 Table and S5 Figure), consistent with previous findings [43]. AWB-killed

131 animals also spent more time to reach the edge of the OP50 lawn when 2-nonanone was

132 present (S2 Table), consistent with the role of AWB in mediating the avoidance of 2-nonanone.

133 Meanwhile, the transgenic animals with genetically killed AWB stayed on OP50 lawn similarly as

134 wild type when 2-nonanone was not present (S3 Table). Together, these results show that AWB

135 regulates the integrated response by mediating the response to the unisensory repellent 2-

136 nonanone.

138 Next, we sought additional sensory neurons that regulated the integrated behavioral decision.

139 Previous studies identify several sensory neurons that respond to the smell of the E. coli strain

140 OP50 or mediate the behavioral response to the presence or removal of food [22, 44, 48-51]. To

141 examine the potential role of these sensory neurons in our multisensory integration paradigm,

142 we first tested a null mutation ky4 in odr-7, which encoded a putative DNA-binding nuclear

143 receptor that specified the function of the AWA sensory neuron [52], a null mutation $p 680$ in

144 che-1, which encoded a zinc finger transcription factor required for the development and 
145 function of the ASE sensory neuron [53], transgenic animals that selectively expressed a cell-

146 death activator EGL-1 [54] in the AQR, PQR and URX neurons or the $\mathrm{CO}_{2}$-sensing BAG

147 sensory neuron [28-30, 55-57]. We also tested transgenic animals selectively expressing a cell-

148 death inducing caspase, or twk-18(gf) that encoded a constitutively active form of the potassium

149 channel TWK-18 [58], or tetanus toxin that eliminated the synaptic release [59] in the ASI, AWC,

150 ASJ, ADL or ASK neuron [49, 55, 60-64]. We found that all except three of the tested strains

151 were normal. The transgenic animals that contained genetically-killed ASK left the OP50 lawn

152 significantly faster than wild type, and the transgenic animals that contained genetically-killed

153 ASI or expressed the tetanus toxin in ADL left the OP50 lawn significantly more slowly than wild

154 type (Figure 2B-2D and S4 Table). Because the transgenic animals defective in the function of

155 ASK or ASI or ADL are not deficient in avoiding 2-nonanone in our standard chemotaxis assay,

156 in their ability to remain on OP50 lawn when 2-nonanone is not present, as well as in moving to

157 the edge of the OP50 lawn with the presence of 2-nonanone (S1-3 Tables), these results

158 together indicate that the sensory neurons ASK, ASI and ADL modulate how rapidly the

159 behavioral decision to leave the repellent-paired food lawn is made.

161 Multisensory integration requires peptidergic and the TGF- $\beta$ pathways

162 To characterize the mechanisms underlying multisensory integration of food and 2-nonanone,

163 we examined mutants that were defective in biosynthesis of neurotransmitters. We tested

164 effects of mutating tph-1 that encoded tryptophan hydroxylase required for the production of

165 serotonin [65], cat-2 that encoded tyrosine hydroxylase needed for the synthesis of dopamine

166 [66], $t d c-1$ that encoded tyrosine decarboxylase required for the synthesis of tyramine and

167 octopamine, or tbh-1 that encoded tyramine beta hydroxylase required for the production of

168 octopamine [67]. Interestingly, all of these mutants exhibited wild-type behavioral decision when

169 they were exposed to 2-nonanone on an OP50 food lawn (Figure 3A-D and S6 Figure). These

170 results show that serotonin, dopamine, tyramine or octopamine are not required for 2- 
171 nonanone-dependent food leaving, although these neurotransmitters regulate many food-

172 dependent sensorimotor responses ([32] and references therein).

173

174 Next, we examined the function of neuropeptide-encoding genes. We first found that mutations

175 in the $k p c-1(g k 8)$ and egl-3(n150) that disabled two of the four known peptide pre-processing

176 enzymes in C. elegans [68-70], delayed the decision to leave the food lawn that was paired with

177 2-nonanone (Figure 3E and 3F), suggesting the modulatory role of peptides or growth factors in

178 promoting the integrated decision to leave the tainted food lawn. Next, we screened many

179 mutations in genes encoding peptides or growth factors. We focused on the available mutations

180 that did not generate any gross defect in either development or locomotion and identified three

181 mutations that significantly altered the wild-type decision. The canonical mutations, e1372, or a

182 deletion, ok3125, in daf-7 that encoded a TGF- $\beta$ ligand that regulated development, metabolism

183 and host-pathogen recognition [71-73], significantly delayed the decision to leave the OP50

184 lawn tainted with 2-nonanone (Figure 3G and 3I). A deletion mutation tm2984 in nlp-7, which

185 encoded a neuropeptide-like protein that regulated stress response, egg-laying, life span and

186 modulation of aversive responses to noxious stimuli [74-77], similarly delayed the decision to

187 leave the lawn (Figure $3 \mathrm{H}$ ). However, the mutations in daf-7 or nlp-7 did not generate any

188 detectable defect in the chemotactic response to 2-nonanone alone, or the tendency to leave

189 the OP50 lawn when no repellent was present, or the ability to move to the edge of the lawn

190 when 2-nonanone was present (S1-3 Tables). In addition, expressing the genomic fragment

191 containing the regulatory and coding regions of daf-7 or nlp-7 fully rescued the defect of the

192 respective mutant animals in making the decision to leave the lawn that was paired with 2-

193 nonanone (Figure 3I and 3J). Together, these results indicate that TGF- $\beta / D A F-7$ and NLP-7

194 promote the food-leaving decision when 2-nonanone is present. 
197 The C. elegans TGF-ß/DAF-7 regulates several physiological processes through the conserved

198 type I and type II TGF- $\beta$ receptor, DAF-1 and DAF-4, respectively $[78,79]$. DAF-7 is found in the

199 sensory neurons OLQ, ADE and ASI, all of which are implicated in sensing bacteria [23, 71, 72,

$20080,81]$. DAF-7 produced by ASI regulates the satiety-induced quiescence, the entry into an

201 alternative developmental stage under the environmental stress, and the modulation of the

202 lifespan by dietary restriction, and responds to the abundance of food [72, 80-83]. The

203 expression of daf-7 is induced in the sensory neuron ASJ upon exposure to pathogenic bacteria

204 and DAF-7 in ASJ regulates the avoidance of the pathogen through DAF-1 and DAF-4 receptors

205 [71]. In addition, through DAF-1 and DAF-4, DAF-7 regulates metabolism and fat accumulation

206 [73]. Here, we showed that mutating daf-7 delayed the decision to leave the food lawn when 2-

207 nonanone was present (Figure 3G). To identify the source of the DAF-7 signal regulating

208 multisensory integration, we tested the transgenic animals that selectively expressed a wild-type

209 daf-7 cDNA in subsets of daf-7-expressing neurons in daf-7 mutant animals for potential

210 rescuing effects. We found that expressing daf-7 selectively in ASI (Pstr-3::daf-7 [71]) did not

211 rescue the defects in the integrated response; but expressing daf-7 in ADE (Pcat-2::daf-7) or

212 OLQ (Pocr-4::daf-7) sensory neurons using cell-selective promoters [84-86] rescued the

213 delayed leaving phenotype in the daf-7(e1372) mutant animals (Figure 3K and 3L, S7 Figure).

214 In addition, we found that the canonical mutation in the type I and type II TGF- $\beta$ receptor, daf-

$2151(m 40)$, similarly delayed the decision to leave the OP50 lawn paired with 2-nonanone (Figure

216 4A). Expressing either the genomic DNA fragment of daf-1 or the daf-1 cDNA selectively in the

217 interneurons RIM and RIC (Pdaf-1::daf-1 or Ptdc-1::daf-1; $[71,73])$ fully rescued the defect in

218 the daf-1(m40) mutant animals (Figure 4B and 4C), while expressing daf-1 in sensory neurons

219 (Pbbs-1::daf-1 or Posm-6::daf-1; [71]) was not sufficient to rescue (Figure 4D and S8 Figure).

220 Together, these results indicate that the TGF- $\beta / D A F-7$ signal produced by the ADE or the OLQ

221 sensory neurons acts through the type I TGF- $\beta$ receptor DAF-1 in RIM and/or RIC neurons to

222 promote repellent-dependent leaving of the food lawn. 
224 To further interrogate the role of the RIM/RIC neurons in multisensory integration, we examined

225 the transgenic animals that expressed a histamine-gated chloride channel in the RIM and RIC

226 neurons under the histamine-treated condition [87] or the transgenic animals that expressed

227 tetanus toxin [59] in RIM and RIC. We found that these transgenic animals were normal in

228 leaving the OP50 lawn when 2-nonanone was present (Figure 4E and 4F). Since neither the

$229 t d c-1$ (n3419) mutant animals that lacked tyramine and octopamine nor the tbh-1(n3247) mutant

230 animals that lacked octopamine is defective in their decisions to leave the OP50 lawn paired

231 with 2-nanone (Figure 3), together, our results suggest that RIM/RIC and the release of the

232 neurotransmitter tyramine and octopamine from these neurons may be suppressed during the

233 integrated response to the simultaneously present food lawn and 2-nonanone. To further

234 interrogate the role of tyramine or octopamine signaling in the daf-7- and daf-1-dependent

235 integrated response, we tested how removing tyramine and/or octopamine affects the delayed

236 food leaving in the daf-7(e1372) or daf-1(m40) mutant animals. Interestingly, both of the daf-

237 1(m40); tbh-1(ok1196) and the daf-7(e1372); tbh-1(ok1196) double mutant animals [19]

238 behaved like the daf-1(m40) and the daf-7(e1372) single mutants, respectively (Figure 4G). In

239 contrast, the mutation in $t d c-1$ (ok914) strongly suppressed the delayed decision phenotype in

240 both daf-7(e1372) and daf-1(m40) mutant animals (Figure 4H and 4I). While TDC-1 is needed

241 for the production of tyramine and octopamine in both RIM and RIC, TBH-1 is only needed for

242 the biosynthesis of octopamine in RIC [67]. Together, these results show that the TGF- $\beta / D A F-7$

243 regulates the decision between staying on a food lawn versus avoiding a repellent through the

244 canonical signaling pathway and that the DAF-7 peptidergic signal produced from ADE or OLQ

245 inhibits the tyramine neurotransmission of RIM and/or RIC to promote the decision to leave the

246 food-lawn that is paired with 2-nonanone. 
To better characterize the neural circuits underlying multisensory integration, we probed the potential interneurons that regulated the decision between staying on the food lawn versus avoiding 2-nonanone. We focused on the interneurons AIY, AIB, and the command

252 interneurons, all of which regulate locomotion [22, 88]. AIY and AIB are also the major

253 interneurons postsynaptic to the sensory neurons that respond to the bacterial food or the

254 repellent 2-nonanone [40]. To disrupt the function of AIY, we selectively expressed in AIY a

255 gain-of-function isoform of a potassium channel TWK-18 [58] to inhibit the activity of AIY (Pttx-

256 3::twk-18(gf)) or the tetanus toxin $(P t t x-3:: T e T x)$ to block synaptic release. We also tested the

$257 t t x-3(m g 158)$ mutants that failed to develop AIY interneurons [89]. All three mutations delayed

258 the decision to leave the lawn (Figure 5A - 5C). However, these manipulations do not disrupt the

259 ability to reach the edge of the food lawn during 2-nonanone-dependent food leaving, to avoid

260 2-nonanone alone, or to stay on OP50 lawn when no repellent was present (S1-3 Tables). In

261 contrast, selectively expressing the tetanus toxin in the AIB interneurons or treating the

262 transgenic animals expressing the histamine-gated chloride channel in AIB with histamine did

263 not significantly alter the decision to leave the OP50 lawn that was paired with 2-nanonone

264 (Figure 5D and 5E). Together, these results indicate that the activity and the synaptic output of

265 the AIY interneurons promote the decision to leave the food lawn paired with 2-nonanone, while

266 AIB is dispensable for the decision-making. Next, we examined transgenic animals that

267 expressed the tetanus toxin with the $n m r-1$ promoter or the $g / r-1$ promoter. The $n m r-1$ promoter

268 is expressed in a few command interneurons including AVA, AVB, AVD, AVE and PVC, while

269 the glr-1 promoter is expressed in several head motor neurons in addition to the $\mathrm{nmr}-1$ -

270 expressing interneurons [90]. Interestingly, both transgenic lines left the 2-nonanone paired food

271 lawn more than wild type (Figure 5F and 5G). However, these transgenic animals are normal in

272 2-nonanone avoidance in the absence of food or spontaneous food leaving. They also do not

273 reach the edge of the lawn more rapidly than wild type (S1-3 Tables). Together, these results

274 show that different downstream neurons modulate the decision to leave the repellent tainted 
275 food lawn in opposite ways by promoting or inhibiting the decision-making process. These

276 neurons may act as the convergent sites to process multiple sensory signals in order to

277 generate specific behavioral outputs.

278

279 Multisensory integration is regulated by a common set of modulators

280 Next, we asked whether the molecular and circuit mechanisms underlying the integrated

281 response to the OP50 food lawn paired with 2-nonanone were shared by the integrated

282 responses to different pairing of attractive foods and repulsive odorants. We paired the OP50

283 lawn with various repellants, including 100\% 1-octanol and 100\% benzaldehyde. While

284 benzaldehyde is attractive at low concentrations [24], 100\% benzaldehyde strongly repels $C$.

285 elegans in a way that is dependent on the function of the sensory neuron AWB [91-93]. We

286 found that a drop of $100 \%$ benzaldehyde first repelled the animals to the edge of the OP50 food

287 lawn and then in about 10-15 minutes started to repel the animals off the food lawn (Figure 6A

288 and S10 Movie). Interestingly, 1-octanol failed to stimulate food leaving under our experimental

289 conditions (Figure 6A). We also paired a lawn of Comamonas sp with 100\% 2-nonanone.

290 Comamonas is an attractive food source for C. elegans [41]. We found that pairing a

291 Comamonas bacterial lawn with 100\% 2-nonanone repelled C. elegans off the lawn similarly as

292 the OP50 lawn paired with 2-nonanone (Figure 7A). Interestingly, we found that several

293 modulators, particularly TGF- $\beta$ /DAF-7, the TGF- $\beta$ receptor DAF-1, and the sensory neurons

294 ASK, that regulated the integrated response to an OP50 lawn paired with $100 \%$ 2-nonanone

295 also similarly regulated the integrated response to OP50 lawn paired with $100 \%$ benzaldehyde

296 and the integrated response to the Comamonas lawn paired with 100\% 2-nonanone (Figure 6

297 and 7). Together, these results indicate that a common set of modulators and signaling

298 mechanisms regulates integrated behavioral decision on whether to leave or stay on an

299 attractive food lawn paired with an odorant repellent. 


\section{Discussion}

302 Many organisms can combine information from multiple simultaneously present sensory cues to

303 regulate behavioral outputs [1-8, 32]. While the importance of integrated behavioral responses

304 to multiple sensory stimuli is appreciated, the underlying molecular and signaling mechanisms

305 are not well understood. Using our behavioral paradigm for multisensory integration, we

306 characterize the modulators and signaling pathways that regulate a decision to leave a food

307 lawn that is paired with a repulsive odorant. These findings reveal a new function of a conserved

308 TGF- $\beta$ that modulates decision-making by regulating the tyramine signal from a set of central

309 neurons. Our results elucidate a set of common molecular and neuronal factors that mediate

310 decision-making when the worm is presented with different pairs of stimuli generated by an

311 attractive food and a repulsive odorant (Figure 8).

313 Specific sensory neurons regulate multisensory integration

314 One potential mechanism to regulate a coherent behavioral response to multiple simultaneously

315 present sensory cues is to utilize sensory neurons that are capable of perceiving some or all of

316 the cues. These types of sensory responses can involve either activation or inhibition of certain

317 sensory neurons that detect distinct stimuli. Worms are capable of sensing both food signals

318 and a range of repulsive cues ([32] and the references therein). Here, we characterize the

319 functions of several sensory neurons in regulating the repellent-dependent food leaving when $C$.

320 elegans is exposed to an attractive food lawn concurrently with a repulsive odorant. We confirm

321 the requirement of the AWB sensory neuron that is known to sense repellents, including 2-

322 nonanone and $100 \%$ benzaldehyde [43, 45, 91]. AWB also responds to bacterial food [44, 51].

323 Previous studies identify the role of AWB in promoting food leaving under malnourished

324 conditions [94], suggesting the involvement of AWB in integrating the nutritional state with the 
325 food signals. Thus, AWB may regulate the integrated response by simultaneously processing

326 food smells and repulsive odorants.

328 Interestingly, we also uncover a novel role of three sensory neurons that modulate the decision

329 to leave a food paired with a repulsive odorant. We show that the ASK sensory neuron

330 suppresses the integrated food-leaving decision, while the ASI and ADL sensory neurons

331 promote it. In contrast, we find that several other sensory neurons previously implicated in

332 mediating responses to food-related cues, including AWA, ASE, AWC, ASJ, BAG, AQR, PQR or

333 URX $[44,48,49,51,71]$, are dispensable in regulating the integrated behavioral response to the

334 food lawn paired with 2-nonanone (S4 Table). In addition, our results suggest that the effect of

335 removing either ASK or ASI or ADL on the decision-making does not result from the altered

336 chemotactic response to 2-nonanone as a unisensory cue or to the OP50 bacterial lawn alone

337 (S1-3 Tables). These results together reveal a specific function of ASK, ASI and ADL in

338 integrating the food signals with the repellent to generate a decision between two sensory cues

339 of opposing valence.

341 Previous studies show that ASK and ASI sensory neurons respond to E. coli OP50 by changing

342 the intracellular calcium levels [51, 95]. Both ASI and ASK are involved in evaluating the food

343 environment. ASI also mediates the balance between food intake and fat storage, as well as

344 experience-dependent changes in food response [37, 73, 80-82, 96]. ASK regulates responses

345 to pheromones and plays a role in food leaving in mutants that are significantly food-deprived

346 and modulates locomotion during pre-exposure to unpredictable food environments $[49,63,64$,

347 94]. The ADL sensory neuron has been shown to modulate the responses to octanol,

348 pheromone and the preference for certain food odors [64, 77], suggesting that ADL mediates

349 various context-dependent sensory responses to modulate behavior and decision-making. In

350 our present study, we propose that ASI, ADL and ASK neurons represent the strength of the 
351 food signals in an antagonistic manner to mediate a balanced behavioral decision between an

352 attractive food and a repulsive odorant.

354 Neuropeptides and growth factors modulate multisensory integration

355 Although previous studies characterize the function of neuromodulators, including

356 neuropeptides and growth factors, in modulating olfactory responses and nutrition-dependent

357 state of the nervous system, how neuromodulatory signals regulate a behavioral decision that

358 integrates cues of opposing values is not well understood. Here, we characterize the role of

359 neuromodulatory molecules, including a conserved TGF- $\beta$, in modulating the decision to leave a

360 food lawn when a repulsive odorant is presented together with the lawn.

362 Neuropeptides and growth factors have been implicated in the context-dependent modulation of

363 several sensorimotor responses in C. elegans [3, 34, 77, 96-98]. Here, we identify the

364 neuropeptidergic signaling mechanisms based on the examination of the neuropeptide

365 processing mutants, egl-3 and $k p c-1$, and identification of the NLP-7 peptide and the TGF-

$366 \quad \beta / D A F-7$ that modulate the decision to leave a food lawn paired with a repulsive odorant.

367 Mutating $n / p-7$ or daf-7 delayed the decision to leave the lawn. In contrast, mutating genes that

368 encode several other peptides that are expressed in different sensory neurons and have been

369 shown to signal contextual cues or previous experience or food signals, including ins-6, ins-7,

$370 \quad n / p-1, n / p-9, n / p-24$ and flp-19 [62, 77, 96, 97, 99], does not have a significant effect (S4 Table),

371 suggesting a specific function of $n / p-7$ and daf-7 in regulating the decision-making process. $n / p-$

3727 is expressed in several amphidial sensory neurons that respond to contextual cues and NLP-7

373 delays the acute avoidance of a noxious stimulus, 1-octanol [74-77, 100]. This effect is in

374 contrast with that of mutating $n / p-7$ in the integrated behavioral response, where NLP-7

375 promotes the decision to leave the food in order to avoid the repulsive odorant. Our results 
together with the previous findings characterize distinct functions of the NLP-7 neuropeptide in regulating multisensory integration versus context-dependent avoidance of noxious stimuli.

\section{Previous studies show that the DAF-7 pathway regulates dauer formation, food intake, fat} storage, as well as avoidance of pathogenic bacteria after prolonged exposure. The functions of DAF-7 in these physiological events depend on its expression in the sensory neurons ASI and/or ASJ [71-73]. Here, we show that DAF-7 promotes the decision to leave the food lawn paired with a repulsive odorant and that different from its previously identified role, the function of DAF-7 in regulating multisensory decision depends on the expression of daf-7 in either the ADE or the OLQ sensory neurons. Our results are the first to characterize the function of daf-7 produced by ADE or OLQ. ADE is one of the dopaminergic neurons in the worm nervous system [101]. However, we did not see any phenotype in the cat-2 mutants that were defective in dopamine synthesis (Figure 3), suggesting that the function of ADE in regulating the integrated response to food and repellent is independent of dopamine. Both ADE and OLQ have been previously implicated in mechanosensation - OLQ is implicated in sensing the gentle touch delivered to the nose and ADE contributes to the slowing response when a worm enters a bacterial lawn $[23,31,102]$. We propose that $A D E$ and OLQ regulate the integrated response to a food lawn paired with a repellent by representing the mechanical stimulus that a worm senses from the food lawn.

We further show that the canonical TGF- $\beta$ receptor DAF-1 acts in the interneurons RIM and RIC to regulate the decision to leave the food lawn paired with a repulsive odorant. Interestingly, inhibiting the activity of RIM and RIC, or blocking the synaptic outputs of these neurons, or disrupting the biosynthesis of the common neurotransmitter of these neurons, tyramine, does not significantly change the decision-making process. However, disrupting the production of tyramine, but not octopamine, in these neurons suppresses the slow-decision phenotype in the 
daf-1 or daf-7 mutant animals (Figure 3 and 4). Together, these results indicate that the DAF-

7/DAF-1 pathway promotes the decision to leave by inhibiting the tyramine signaling from these interneurons. This regulatory mechanism of DAF-7 is reminiscent of that in feeding, where DAF7 promotes the pumping rate by inhibiting the output from the RIM and/or RIC neurons. However, different from the function of DAF-7 in regulating feeding that is dependent on tyramine and/or octopamine [73], DAF-7 modulates the signal of tyramine, but not octopamine, to regulate the decision to leave a food paired with the repellant 2-nanonone.

The RIM and RIC neurons have been previously implicated in various sensorimotor responses, as well as the context-dependent locomotory and feeding behaviors $[67,73,87,100,103]$. Our results that characterize RIM/RIC as the downstream neurons of the TGF- $\beta$ /DAF-7 signal in regulating the decision to leave a tainted food lawn further reveal RIM/RIC as one of the central sites where different sensory signals converge to generate appropriate behavioral outputs.

Previously, TGF- $\beta$ signals have been implicated in various neuronal functions, including learning and memory, neural plasticity in the forms of LTP and LTD, synaptic formation, dendritic development, and regulation of the function of the neural-muscular junctions [104-107]. Defects in TGF- $\beta$ pathways have been implicated in the pathology of neurological disorders, such as schizophrenia, depression, anxiety and Alzheimer's disease [108-110]. Our work reveals a new role for TGF- $\beta$ signals in regulating decision-making, when sensory cues of opposing valance are simultaneously present.

\section{Specific interneurons modulate 2-nonanone-dependent food leaving in C. elegans.}

The ability to integrate multiple types of sensory stimuli requires not only the responses across peripheral sensory areas, but also the signal processing in downstream network of interneurons $[1,3,5-8,111]$. In C. elegans, a number of sensorimotor responses are modulated by specific contexts via the functions of several interneurons [34, 97, 100,112]. However, how interneurons 
mediate decision-making during multisensory behavior is not fully characterized. Here, by

examining a number of interneurons that are downstream of the sensory neurons that detect the food-related cues and the repulsive odorant, we find that the AIY interneuron and command

431 interneurons, as well as motor neurons, play a modulatory role in 2-nonanone-dependent food

432 leaving. Disrupting the function of AIY significantly delays the decision to leave the food paired

433 with 2-nonanone, without altering the response to either of the two cues that is presented alone.

434 The AIY interneuron receives synaptic inputs from sensory neurons that detect olfactory,

435 gustatory and thermal information. Previous studies implicate AIY in integrating simultaneously

436 present aversive and attractive cues in olfactory plasticity and in food and serotonin-dependent

437 modulation of sensorimotor responses [34, 97, 112-114]. We propose that AIY may act as an

438 integrating site that receives and processes signals from the food and the repellent 2-nonanone

439 during multisensory integration. In contrast, we did not detect a role for the interneuron AIB with

440 our assay, suggesting the functional diversity among the interneurons in modulating 2-

441 nonanone-dependent food leaving. Our study also implicates the g/r-1-and $n m r$-1-expressing

442 neurons in promoting the repellent-dependent food leaving. It is conceivable that some of the

$443 n m r-1$-expressing command interneurons and the glr-1-expressing command interneurons or

444 head motor neurons may serve as the downstream-modulated targets for the integrated

445 behavioral response.

\section{A common set of modulators regulate repellent-dependent food leaving}

448 For freely feeding animals, such as C. elegans, appropriate behavioral responses to food

449 sources paired with other sensory cues are critical for survival, because food can be easily

450 contaminated with toxins. To understand to what extent the identified modulators generally

451 regulate integrated responses to foods and repellents, we paired the E. coli strain OP50 with

452 either 100\% 2-nonanone or $100 \%$ benzaldehyde. We also paired $100 \% 2$-nonanone with a

453 second food, Comamonas. Interestingly, we found that the TGF-B/DAF-7 pathway and the ASK 
sensory neuron regulate the integrated responses to these two different pairs of foods and repellents. Avoidance of both $100 \%$ 2-nonanone and $100 \%$ benzaldehyde depends on the function of the olfactory sensory neurons AWB $[43,45,91,115]$. Meanwhile, Comamonas sp

457 also serves as an attractive food source to the worms [41]. It is conceivable that a common set

458 of modulators represent the contexts where the worm needs to evaluate the opposing values

459 provided by a source of nutrients and a potential threat to generate a behavioral decision.

$461 \quad$ Figure legends

462 Fig 1. C. elegans performs multisensory integration to leave food paired with a repulsive odorant 2-nonanone.

464 (A) A schematic of 2-nonanone-dependent food leaving assay.

465 (B) The time course for worms leaving OP50 lawn that is paired with 2-nonanone of different 466 concentrations over 60 minutes, $n=2$ assays for $10 \%$ and $n=3$ assays each for $30 \%, 50 \%$ and $467 \quad 100 \%$.

468 (C) More worms leave the OP50 food lawn paired with 100\% 2-nonanone ( $\mathrm{n}=4$ assays) than

469 the OP50 lawn paired with $10 \%$ 2-nonanone ( $n=5$ assays). Bar graph represents the

470 percentage of worms outside the lawn 15 minutes after the assay starts.

471 (D) The time taken for worms to reach the edge of the OP50 food lawn when the lawn is paired

472 with either $10 \%$ or $100 \%$ 2-nonanone, $n=2$ assays each.

473 (E) I - IV, Sample images of wild-type animals leaving an OP50 lawn that is paired with $100 \% 2$ -

474 nonanone at different time points of the 60-minute assay.

475 For B-D, Mean \pm SEM, Student's $t$ test, ${ }^{* *} p \leqslant 0.01$, n.S., not significant. 
(A-D) The transgenic animals that either lack the functional AWB sensory neuron by selectively expressing the gain-of-function isoform of an amiloride-sensitive sodium channel MEC-4 (A, $p A W B:: m e c-4(d), \mathrm{n}=5$ assays each) or lack the ASI sensory neuron by expressing a cell death promoting molecule caspase (B, pASI::caspase, $\mathrm{n}=7$ assays for wild type and 8 assays for the

482 transgenic animals) or are defective in the synaptic transmission of the ADL sensory neuron by 483 expressing the tetanus toxin (D, $p A D L:: T e T x, \mathrm{n}=5$ assays for wild type, 4 assays for the

484 transgenic animals, and 3 assays for non-transgenic siblings) display a delayed decision to 485 leave the OP50 lawn paired with 100\% 2-nonanone; while the transgenic animals that express caspase in the ASK sensory neuron (C, pASK::caspase, $\mathrm{n}=9$ assays each) display a faster decision to leave.

Each bar graph reports the average percentage of worms outside the lawn 15 minutes after the assay starts. Mean \pm SEM, Student's $t$-test, ${ }^{*} p \leqslant 0.05,{ }^{* * *} p \leqslant 0.001$.

Fig 3. NLP-7 and TGF- $\beta$ /DAF-7 modulate the decision to leave the OP50 food lawn paired with 2-nonanone.

(A-D) The mutant animals that are defective in the biosynthesis of the neurotransmitter serotonin (A, tph-1(mg280), $\mathrm{n}=2$ assays each), or dopamine (B, cat-2(e1112), $\mathrm{n}=4$ assays each), or tyramine and octopamine (C, $t d c-1(n 3419), \mathrm{n}=2$ assays each), or octopamine (D, tbh1(n3247), $\mathrm{n}=3$ and 4 assays for wild type and tbh-1 mutants, respectively) display a normal decision to leave the OP50 food lawn that is paired with 2-nonanone. (E-K) Mutations in the genes encoding the neuropeptide processing enzymes, $k p c-1(\mathbf{E}, \mathrm{n}=4$ and 5 assays for wild type and $k p c-1$ mutant, respectively), or egl-3 (F, $n=4$ and 6 assays for wild type and egl-3 mutant, respectively), or a TGF- $\beta$-encoding gene $\operatorname{daf}-7$ (G, $n=6$ and 5 
leave the OP50 food lawn paired with 2-nonanone, and expressing the genomic DNA of nlp-7 (I, $\mathrm{n}=6,7$ and 4 assays for wild type, transgenic animals and non-transgenic siblings, respectively) or daf-7 ( $J, n=4$ assays each for wild type, transgenic animals and non-transgenic siblings) rescues the delayed food leaving phenotype of the respective mutant animals.

507 K) Expressing the wild-type daf-7 cDNA in the sensory neurons ADE rescues the delayed 508 decision in the daf-7(e1372) mutant animals, $n=4$ assays each for wild type, transgenic 509 animals and non-transgenic siblings, respectively.

510 (L) Expressing the wild-type daf-7 cDNA in the sensory neurons OLQ also rescues the delayed 511 decision in the daf-7(e1372) mutant animals, $\mathrm{n}=3$ assays for wild type, 3 assays for transgenic 512 animals and 2 assays for non-transgenic siblings, respectively.

513 Each bar graph reports the average percentage of worms outside the lawn 15 minutes after the 514 start of the assay, mutants are compared with wild-type animals and transgenic animals are 515 compared with non-transgenic siblings using Student's $t$-test, ${ }^{*} p \leq 0.05,{ }^{* *} p \leq 0.01,{ }^{* * *} p \leq$ $516 \quad 0.001$, n.s., not significant.

Fig 4. The TGF- $\beta$ receptor DAF-1 acts in the RIM and RIC neurons to mediate 2nonanone-dependent food leaving.

520 (A-D) Mutating daf-1 that encodes the type I TGF- $\beta$ receptor delays the decision to leave the 521 OP50 lawn paired with $100 \%$ 2-nonanone (A, $n=8$ assays each), and expressing the genomic 522 DNA of daf-1 (B, $n=6$ assays each) or a wild-type daf-1 cDNA in the RIM and RIC neurons (C, $523 \mathrm{n}=6,6$ and 5 assays for wild type, transgenic animals and non-transgenic siblings,

524 respectively) in the daf-1 $(\mathrm{m} 40)$ mutant animals rescues the delayed decision, but expressing 525 wild-type daf- 1 in the sensory neurons $(\mathbf{D}, \mathrm{n}=3,5$ and 2 assays for wild type, transgenic 526 animals and non-transgenic siblings, respectively) does not rescue. Mutants are compared with 527 wild type and transgenic animals are compared with non-transgenic siblings with Student $t$-test. 
528 (E-F) Inhibiting the activity of the RIM and RIC neurons by selectively expressing a histaminegated chloride channel $(E, n=2$ and 4 assays for wild type and transgenic animals,

530 respectively) or blocking the synaptic release from these neurons by selectively expressing the

531 tetanus toxin ( $F, n=2$ assays each) does not alter the decision to leave the OP50 food lawn

532 paired with 100\% 2-nonanone. Transgenic animals are compared with wild type.

533 (G-I) Removing octopamine signaling in the daf-7(e1372) or daf-1(m40) mutants with a mutation

534 that disrupt biosynthesis of octopamine tbh-1(ok1196) does not suppress the delayed leaving

535 from the OP50 lawn paired with 100\% 2-nonanone (G, $n=6$ assays for wild type; $n=4$ assays

536 for daf-7 mutants; $\mathrm{n}=2$ assays for daf- 1 mutants; $\mathrm{n}=3$ assays for daf-7;tbh-1 double mutants;

$537 \mathrm{n}=2$ assays for daf-1;tbh-1 double mutants), but removing the tyramine and the octopamine

538 signals with the mutation in $t d c-1(0 k 914)$ in either the daf-7(e1372) $(\mathbf{H}, \mathbf{n}=6,5$ and 4 assays for

539 wild type, daf-7 mutants and daf-7;tdc-1 double mutants, respectively) or the daf-1 $(m 40)(\mathbf{I}, \mathrm{n}=$

5405,4 and 5 assays for wild type, daf- 1 mutants and daf-1;tdc-1 double mutants, respectively)

541 mutant animals suppresses the delay-decision phenotype in either of the mutant animals.

542 Double mutants were compared with the respective single mutants using student's $t$ test.

543 Each bar graph reports the average percentage of worms outside the lawn 15 minutes after the 544 start of the assay. Mean \pm SEM, ${ }^{* *} p \leqslant 0.01,{ }^{* * *} p \leqslant 0.001$, n.s.; not significant.

Fig 5. Downstream circuit that regulates 2-nonanone-dependent food leaving

547 (A-C) Inhibiting the activity of the AIY interneuron by expressing the gain-of-function isoform of 548 the potassium channel TWK-18 (A, Pttx-3::twk-18(gf), $\mathrm{n}=3$ assays each) or by blocking the 549 synaptic outputs of AIY by expressing tetanus toxin (B, Pttx-3::TeTx, $\mathrm{n}=4$ assays each), or the 550 mutation $t t x-3(m g 158)$ that generates development defects in AIY (C, $n=3$ assays each) delays 551 the decision to leave the OP50 lawn paired with 100\% 2-nonanone. 
552 (D, E) Selectively expressing tetanus toxin (D, Pinx-1::TeTx, $\mathrm{n}=2$ assays each) or the inhibitory

$553 \mathrm{HisCl}$ channel (E, Pinx-1::HisCl, $\mathrm{n}=3$ and 4 assays for wild type and transgenic animals,

554 respectively) in the AIB interneuron does not significantly alter the lawn-leaving decision, when

555 the OP50 lawn is paired with 100\% 2-nonanone.

$556(\mathbf{F}, \mathbf{G})$ Blocking synaptic outputs from the $n m r-1$-expressing neurons $(\mathbf{F}, P n m r-1:: T e T x, \mathrm{n}=3$

557 assays each) or the glr-1-expressing neurons (G, Pglr-1::TeTx, $\mathrm{n}=4$ and 3 assays for wild type

558 and transgenic animals, respectively) enhanced the 2-nonanone-dependent lawn leaving.

559 Each bar graph reports the average percentage of worms outside the lawn 15 minutes after the 560 start of the assay. Mean \pm SEM, mutants are compared with wild-type animals with student's $t$ 561 test, transgenic animals are compared with non-transgenic siblings with student's $t$-test, * $\mathrm{p} \leqslant$

$5620.05,{ }^{* *} p \leqslant 0.01,{ }^{* *} p \leqslant 0.001$, n.s., not significant.

Fig 6. Integrated response to a repellent-paired food lawn is regulated by a common set of factors.

566 (A) Wild-type animals also leave the lawn of OP50 paired with $100 \%$ benzaldehyde; in contrast, 567 paring an OP50 lawn with either $100 \%$ octanol does not repel worms $(n=2$ assays for each 568 condition).

569 (B-E) Genetic ablation of the sensory neuron AWB (B, pAWB::mec-4(d), $\mathrm{n}=3$ assays each) or ASK (C, pASK:::caspase, $\mathrm{n}=3$ assays each) or mutating the genetic components of the TGF-

571 B/DAF-7 pathway (D, daf-7(e1372), $n=3$ assays each; E, daf-1(m40), $n=4$ assays each) alters

572 the decision to leave the benzaldehyde-paired OP50 lawn.

573 Each bar graph reports the average percentage of worms outside the lawn 25 minutes (B, D, E) 574 or 5 minutes $(\mathbf{C})$ after the start of the assay. Mean \pm SEM, mutants are compared with wild-type 575 animals with Student's $t$ test, ${ }^{* *} p \leqslant 0.01,{ }^{* *} p \leqslant 0.001$, n.s., not significant. 
579 (A-D) Genetic ablation of the sensory neuron AWB (A, pAWB::mec-4(d), $\mathrm{n}=2$ assays each) or

580 ASK (B, pASK::caspase, $\mathrm{n}=2$ assays each), or mutating the genetic components of the TGF-

$581 \quad$ B/DAF-7 pathway (C, daf-7(e1372), $\mathrm{n}=4$ assays each; $\mathbf{D}$, daf-1 $(\mathrm{m} 40), \mathrm{n}=2$ assays each) alters

582 the decision to leave the 2-nonanone-paired Comamonas lawn.

583 Each bar graph reports the average percentage of worms outside the lawn 25 minutes $(\mathbf{A})$ or 20

584 minutes (B-D) after the start of the assay. Mean \pm SEM, mutants or transgenic animals are compared with wild type with Student's $t$ test, ${ }^{*} p \leqslant 0.05,{ }^{* *} p \leqslant 0.01$.

\section{Methods}

\section{Strains}

589 C. elegans strains were cultivated under the standard conditions [116]. Hermaphrodites were

590 used in this study. The strains that were used in the study include: PR680 che-1(p680)I,

CX14394 npr-5(ok1583)V, MT15434 tph-1(mg280)II, CB1112 cat-2(e1112)II, MT9455 tbh-

1(n3247)X, RB1161 tbh-1(ok1196)X, RB993 tdc-1(ok914)II, MT13113 tdc-1(n3419)II, DR40 daf-

1(m40)IV, PR691 tax-2(p691)I, PR671 tax-2(p671)I, RB859 daf-22(ok693)II, OH8 ttx-

3(mg158)X, MT150 egl-3(n150)V, CX4 odr-7(ky4)X, CX03572 nlp-9(tm3579)V, ZC2685 npr-

2(ok419)IV, VC48 kpc-1(gk8)I, RB1341 nlp-1(ok1470)X, RB1289 npr-18(ok1388)X, CB1372 
602

603

604

605

606

607

608

609

610

611

612

613

614

615

616

617

618

619

620

621

622

623

624

625

626

627

Podr-1::dsRed], KQ380 daf-1(m40)IV; ftEx205[Ptdc-1::daf-1::gfp; Podr-1::dsRed], KQ252 daf1(m40)IV; ftEx70[Pbbs-1::daf-1::gfp; Podr-1::dsRed], ZD736 daf-7(ok3125)III;qdEx44[Pstr3p::daf-7; Pges-1::gfp], ZD729 daf-7(ok3125)III;qdEx37[Pdaf-7::daf-7; Pges-1::gfp], PY7502 yxIs34[Pceh-36 V::TU813; Pceh-36 V::TU814; Psrtx-1::gfp; Punc-122::dsRed], ZC2393 yxEx1248 [Pttx-3::twk-18(gf)::mCherry; Punc-122::RFP], CX14848 kyEx4866[Pinx1::HisCl1::SL2mCherry; Punc-122::dsRed], CX16040 kyEx5464[Ptdc-1::HisC11::SL2mCherry], ZC1451 yxEx699[Pnmr-1::TeTx::mCherry; Punc-122::dsRED]; QS4 qrls2[Psra-9::mCasp1; Psra-9::gfp; Pelt-2::gfp], PS6025 qrls2[Psra-9::mCasp1; Psra-9::gfp; Pelt-2::gfp]; ZC1552 yxEx749[PgIr-1::TeTx::mCherry; Punc-122::gfp], PY7505 oyls84[Pgpa-4::TU813; Pgcy27::TU814; Pgcy-27::gfp; Punc-122::dsRed], CX3830 kyls102V; kyls104[Pstr-1::mec-4(d); Pstr1::gfp]; CX14637 kyEx4779[Pinx-1::TeTx::mCherry; Punc-122::gfp], CX14993 kyEx4962[Ptdc1::TeTx::mCherry], AX2051 Ex[Pgcy-33::egl-1; Punc-122::dsRed], CX12330 Ex[Psre1::TeTx::mCherry; Punc-122:RFP], CX7102 lin-15B(n765)X; qals2241[Pgcy-36::egl-1; Pgcy35::gfp; lin-15(+)], ZC2752 nlp-7(tm2984)X; yxEx1420[Pnlp-7::nlp-7; Punc-122::gfp], ZC2731 daf-7(e1372)III; yxEx1409[Pcat-2::daf-7; Punc-122::gfp]; ZC2734 daf-7(e1372)III, yxEx1412[Pocr-4::daf-7; Punc-122::gfp]

\section{Behavioral assay for multisensory integration}

On a $5 \mathrm{~cm}$-diameter NGM (Nematode Growth Medium) plate, 20-25 young adult worms were placed on a small $1 \mathrm{~cm}$-diameter round-shaped bacterial lawn made of freshly cultivated $E$. coli OP50 strain and left to acclimatize on the lawn for 1-2 hour. Next, a drop of $1 \mu$ l 2-nonanone (Sigma Aldrich, Cat \# 821-55-6), either 10\% (v/v in 100\% ethanol) or $100 \%$, was placed on the right-hand side of the lawn and $3 \mathrm{~mm}$ away from the lawn. The number of worms on the lawn was counted every 5 minutes for a total of 60 minutes, and the percentage of worms outside the lawn was calculated (Figure 1A and 1B). In some assays, $1 \mu \mathrm{l}$ of $100 \%$ benzaldehyde (Sigma Aldrich, Cat \# 100-52-7) was used, instead of 2-nonanone. The OP50 culture was prepared 
freshly each day by culturing at $27^{\circ} \mathrm{C}$ for $12-15$ hours in NGM medium. For assays using

Comamonas sp for the food lawn, the experiments were performed in the same way, except

that the bacterial strain was cultured with Luria Broth. To determine the time taken to reach the

631 edge of the food lawn, the food lawn was divided into 5 columns with each being $2 \mathrm{~mm}$ wide (S5

632 Fig). The time taken for $90 \%$ of the worms to crawl into the column furthest away from the

633 repellent was recorded. Mutants were compared with wild-type animals tested in parallel, and

634 transgenic animals were compared with non-transgenic siblings or wild-type animals tested in

635 parallel on the same day.

637 The bar graphs in the figures report the percentage of worms outside the lawn at the time point

638 when the significant difference between the tested genotypes was first observed. When there was no significant difference, the bar graphs report the percentage of worms outside the lawn 15 minutes after the start of the assay.

643 To generate a $\mathrm{nlp}-7$ genomic rescue fragment, a $4.7 \mathrm{~kb}$ PCR product was amplified from 644 genomic DNA that included $2.5 \mathrm{~kb} 5$ ' upstream sequence, the $n / p-7$ coding region, and $1 \mathrm{~kb}$ 3' 645 downstream sequence (NLP-7F: 5'-CATGTTTTTGATCATTTTCGAAC-'3 and NLP-7R3'UTR: 5'AATATCGTATGCCAACTTGAAC-'3). The nlp-7 genomic PCR product was injected into the nlp7(tm2984) animals. To generate the construct expressing a wild-type daf-7 cDNA in the OLQ or ADE sensory neurons, the daf-7 cDNA was amplified from PJM016 (Gift from Dr. Dennis Kim and Dr. Joshua Meisel [71]). The daf-7 cDNA product was cloned into a gateway destination

650 vector that contained an unc-54 3'UTR using the Nhe-1 and Kpn-1 sites. Both the promoter

651 regions of ocr-4 (4.0 kb promoter for expression in OLQ) and cat-2 (1.1 kb promoter for

652 expression in ADE) were amplified from genomic DNA (CAT-2F: 

and Pocr-4::daf-7, were generated using LR recombination reactions (Invitrogen). Each transgene was injected at $30-50 \mathrm{ng} / \mu \mathrm{l}$ with the co-injection marker as previously described

$658 \quad[117]$.

\section{Lawn-leaving assay}

661 Lawn-leaving assay was performed and analyzed similarly as the assay for multisensory 662 integration, except that no repulsive chemical was present. Briefly, animals were placed on a 1 $\mathrm{cm}$-diameter round-shaped bacterial lawn of OP50 and left for 10 minutes to acclimatize before examining food leaving over a period of one hour by counting the number of worms that were present on the food lawn every 5 minutes for a total of 60 minutes.

\section{2-nonanone avoidance assay}

668 To examine the avoidance of 2-nonanone, chemotaxis assays were performed essentially as 669 previously described [43]. Briefly, animals were placed in the center of a square plate that was

670 divided into sectors A - F and 2 drops of $1 \mu$ of 2-nonanone was added to one side and 2 drops

671 of $1 \mu \mathrm{l}$ ethanol was added to the opposite side of the plate as control. Approximately 100 worms

672 were used in each assay. Chemotactic avoidance was analyzed by counting the number of

673 worms in the sectors A-B, C-D and E-F with E-F being furthest away from the 2-nonanone point 674 sources (S5 Fig). The avoidance index was calculated as the number of animals in sectors A 675 and $B$ minus the number of animals in the sectors $E$ and $F$ and normalized with the total number 676 of animals in all 6 sectors on plate.

\section{Acknowledgements}


We would like to thank Drs. Kevah Ashrafi, Cori Bargmann, Dennis Kim, Richard Komuniecki and Piali Sengupta for sharing reagents. We also thank members of the Zhang lab for insightful discussion for this project. The research in the Zhang lab is supported by Harvard University (PRISE program for G.L.) and The National Institutes of Health (NIH).

\section{The authors declare no competing interest.}

\section{References}

1. Ohyama T, Schneider-Mizell CM, Fetter RD, Aleman JV, Franconville R, Rivera-Alba M, et al. A multilevel multimodal circuit enhances action selection in Drosophila. Nature. 2015;520(7549):633-9. doi: 10.1038/nature14297. PubMed PMID: 25896325.

2. Ravi S, Garcia JE, Wang C, Dyer AG. The answer is blowing in the wind: free-flying honeybees can integrate visual and mechano-sensory inputs for making complex foraging decisions. J Exp Biol. 2016;219(Pt 21):3465-72. doi: 10.1242/jeb.142679. PubMed PMID: 27591315.

3. Ghosh DD, Sanders T, Hong S, McCurdy LY, Chase DL, Cohen N, et al. Neural Architecture of Hunger-Dependent Multisensory Decision Making in C. elegans. Neuron. 2016;92(5):1049-62. doi: 10.1016/j.neuron.2016.10.030. PubMed PMID: 27866800; PubMed Central PMCID: PMCPMC5147516.

4. Bargmann $\mathrm{Cl}$, Marder E. From the connectome to brain function. Nat Methods. 2013;10(6):483-90. PubMed PMID: 23866325.

5. Sanchez-Alcaniz JA, Benton R. Multisensory neural integration of chemical and mechanical signals. Bioessays. 2017;39(8). doi: 10.1002/bies.201700060. PubMed PMID: 28621811.

6. Chandrasekaran C. Computational principles and models of multisensory integration. Curr Opin Neurobiol. 2017;43:25-34. doi: 10.1016/j.conb.2016.11.002. PubMed PMID: 27918886; PubMed Central PMCID: PMCPMC5447489.

7. Stein BE, Stanford TR, Rowland BA. Development of multisensory integration from the perspective of the individual neuron. Nat Rev Neurosci. 2014;15(8):520-35. PubMed PMID: 25158358; PubMed Central PMCID: PMCPMC4215474.

8. Yau JM, DeAngelis GC, Angelaki DE. Dissecting neural circuits for multisensory integration and crossmodal processing. Philos Trans R Soc Lond B Biol Sci. 2015;370(1677):20140203. doi: 10.1098/rstb.2014.0203. PubMed PMID: 26240418; PubMed Central PMCID: PMCPMC4528815.

9. Rolls ET, Grabenhorst F, Parris BA. Neural systems underlying decisions about affective odors. J Cogn Neurosci. 2010;22(5):1069-82. doi: 10.1162/jocn.2009.21231. PubMed PMID: 19320548.

10. Shiraiwa T. Multimodal chemosensory integration through the maxillary palp in Drosophila. PLoS One. 2008;3(5):e2191. doi: 10.1371/journal.pone.0002191. PubMed PMID: 18478104; PubMed Central PMCID: PMCPMC2364657. 
760

761

762

763

764

765

766

767

768

769

11. Verhagen JV, Engelen L. The neurocognitive bases of human multimodal food perception: sensory integration. Neurosci Biobehav Rev. 2006;30(5):613-50. doi: 10.1016/j.neubiorev.2005.11.003. PubMed PMID: 16457886.

12. Bardgett ME, Depenbrock M, Downs N, Points M, Green L. Dopamine modulates effortbased decision making in rats. Behav Neurosci. 2009;123(2):242-51. doi: 10.1037/a0014625. PubMed PMID: 19331447; PubMed Central PMCID: PMCPMC2791340.

13. Stopper CM, Tse MTL, Montes DR, Wiedman CR, Floresco SB. Overriding phasic dopamine signals redirects action selection during risk/reward decision making. Neuron. 2014;84(1):177-89. doi: 10.1016/j.neuron.2014.08.033. PubMed PMID: 25220811.

14. Birren SJ, Marder E. Neuroscience. Plasticity in the neurotransmitter repertoire. Science. 2013;340(6131):436-7. doi: 10.1126/science.1238518. PubMed PMID: 23620040.

15. Damier P. Why do Parkinson's Disease Patients Sometimes Make Wrong Decisions? J Parkinsons Dis. 2015;5(3):637-42. doi: 10.3233/JPD-150600. PubMed PMID: 26406144.

16. Pedersen A, Goder R, Tomczyk S, Ohrmann P. Risky decision-making under risk in schizophrenia: A deliberate choice? J Behav Ther Exp Psychiatry. 2017;56:57-64. doi: 10.1016/j.jbtep.2016.08.004. PubMed PMID: 27568887.

17. Brandwein AB, Foxe JJ, Butler JS, Russo NN, Altschuler TS, Gomes H, et al. The development of multisensory integration in high-functioning autism: high-density electrical mapping and psychophysical measures reveal impairments in the processing of audiovisual inputs. Cereb Cortex. 2013;23(6):1329-41. doi: 10.1093/cercor/bhs109. PubMed PMID: 22628458; PubMed Central PMCID: PMCPMC3643715.

18. Yeap S, Kelly SP, Reilly RB, Thakore JH, Foxe JJ. Visual sensory processing deficits in patients with bipolar disorder revealed through high-density electrical mapping. J Psychiatry Neurosci. 2009;34(6):459-64. PubMed PMID: 19949722; PubMed Central PMCID: PMCPMC2783437.

19. Manita S, Suzuki T, Homma C, Matsumoto T, Odagawa M, Yamada K, et al. A TopDown Cortical Circuit for Accurate Sensory Perception. Neuron. 2015;86(5):1304-16. doi: 10.1016/j.neuron.2015.05.006. PubMed PMID: 26004915.

20. Talsma D, Senkowski D, Soto-Faraco S, Woldorff MG. The multifaceted interplay between attention and multisensory integration. Trends Cogn Sci. 2010;14(9):400-10. doi: 10.1016/j.tics.2010.06.008. PubMed PMID: 20675182; PubMed Central PMCID: PMCPMC3306770.

21. Carmona S, Hoekzema E, Castellanos FX, Garcia-Garcia D, Lage-Castellanos A, Van Dijk KR, et al. Sensation-to-cognition cortical streams in attention-deficit/hyperactivity disorder. Hum Brain Mapp. 2015;36(7):2544-57. doi: 10.1002/hbm.22790. PubMed PMID: 25821110; PubMed Central PMCID: PMCPMC4484811.

22. Gray JM, Hill JJ, Bargmann Cl. A circuit for navigation in Caenorhabditis elegans. Proc Natl Acad Sci U S A. 2005;102(9):3184-91. doi: 10.1073/pnas.0409009101. PubMed PMID: 15689400; PubMed Central PMCID: PMCPMC546636.

23. Sawin ER, Ranganathan R, Horvitz HR. C. elegans locomotory rate is modulated by the environment through a dopaminergic pathway and by experience through a serotonergic pathway. Neuron. 2000;26(3):619-31. PubMed PMID: 10896158.

24. Bargmann $\mathrm{Cl}$, Hartwieg E, Horvitz HR. Odorant-selective genes and neurons mediate olfaction in C. elegans. Cell. 1993;74(3):515-27. PubMed PMID: 8348618.

25. Bargmann $\mathrm{Cl}$, Horvitz HR. Chemosensory neurons with overlapping functions direct chemotaxis to multiple chemicals in C. elegans. Neuron. 1991;7(5):729-42. PubMed PMID: 1660283.

26. Chalfie M, Sulston JE, White JG, Southgate E, Thomson JN, Brenner S. The neural circuit for touch sensitivity in Caenorhabditis elegans. J Neurosci. 1985;5(4):956-64. PubMed PMID: 3981252. 
802

803

804

805

806

807

808

809

810

811

812

813

814

815

816

817

818

819

820

27. Gray JM, Karow DS, Lu H, Chang AJ, Chang JS, Ellis RE, et al. Oxygen sensation and social feeding mediated by a $\mathrm{C}$. elegans guanylate cyclase homologue. Nature. 2004;430(6997):317-22. doi: 10.1038/nature02714. PubMed PMID: 15220933.

28. Cheung BH, Cohen M, Rogers C, Albayram O, de Bono M. Experience-dependent modulation of C. elegans behavior by ambient oxygen. Curr Biol. 2005;15(10):905-17. doi: 10.1016/j.cub.2005.04.017. PubMed PMID: 15916947.

29. Bretscher AJ, Busch KE, de Bono M. A carbon dioxide avoidance behavior is integrated with responses to ambient oxygen and food in Caenorhabditis elegans. Proc Natl Acad Sci U S A. 2008;105(23):8044-9. doi: 10.1073/pnas.0707607105. PubMed PMID: 18524954; PubMed Central PMCID: PMCPMC2410288.

30. Hallem EA, Sternberg PW. Acute carbon dioxide avoidance in Caenorhabditis elegans. Proc Natl Acad Sci U S A. 2008;105(23):8038-43. doi: 10.1073/pnas.0707469105. PubMed PMID: 18524955; PubMed Central PMCID: PMCPMC2430355.

31. Kaplan JM, Horvitz HR. A dual mechanosensory and chemosensory neuron in Caenorhabditis elegans. Proc Natl Acad Sci U S A. 1993;90(6):2227-31. PubMed PMID: 8460126; PubMed Central PMCID: PMCPMC46059.

32. Ghosh DD, Nitabach MN, Zhang Y, Harris G. Multisensory integration in C. elegans. Curr Opin Neurobiol. 2017;43:110-8. doi: 10.1016/j.conb.2017.01.005. PubMed PMID: 28273525; PubMed Central PMCID: PMCPMC5501174.

33. Hao Y, Yang W, Ren J, Hall Q, Zhang Y, Kaplan JM. Thioredoxin shapes the C. elegans sensory response to Pseudomonas produced nitric oxide. Elife. 2018;7. Epub 2018/07/18. doi: 10.7554/eLife.36833. PubMed PMID: 30014846; PubMed Central PMCID: PMCPMC6066330. 34. Flavell SW, Pokala N, Macosko EZ, Albrecht DR, Larsch J, Bargmann CI. Serotonin and the neuropeptide PDF initiate and extend opposing behavioral states in C. elegans. Cell. 2013;154(5):1023-35. doi: 10.1016/j.cell.2013.08.001. PubMed PMID: 23972393; PubMed Central PMCID: PMCPMC3942133.

35. Harris G, Mills H, Wragg R, Hapiak V, Castelletto M, Korchnak A, et al. The monoaminergic modulation of sensory-mediated aversive responses in Caenorhabditis elegans requires glutamatergic/peptidergic cotransmission. J Neurosci. 2010;30(23):7889-99. doi: 10.1523/JNEUROSCI.0497-10.2010. PubMed PMID: 20534837; PubMed Central PMCID: PMCPMC3005568.

36. Ezcurra M, Tanizawa Y, Swoboda P, Schafer WR. Food sensitizes C. elegans avoidance behaviours through acute dopamine signalling. EMBO J. 2011;30(6):1110-22. doi: 10.1038/emboj.2011.22. PubMed PMID: 21304491; PubMed Central PMCID: PMCPMC3061029.

37. Komuniecki R, Hapiak V, Harris G, Bamber B. Context-dependent modulation reconfigures interactive sensory-mediated microcircuits in Caenorhabditis elegans. Curr Opin Neurobiol. 2014;29:17-24. doi: 10.1016/j.conb.2014.04.006. PubMed PMID: 24811318. 38. de Bono M, Maricq AV. Neuronal substrates of complex behaviors in C. elegans. Annu Rev Neurosci. 2005;28:451-501. doi: 10.1146/annurev.neuro.27.070203.144259. PubMed PMID: 16022603.

39. Bargmann $\mathrm{Cl}$. Neurobiology of the Caenorhabditis elegans genome. Science. 1998;282(5396):2028-33. PubMed PMID: 9851919.

40. White JG, Southgate E, Thomson JN, Brenner S. The structure of the nervous system of the nematode Caenorhabditis elegans. Philos Trans R Soc Lond B Biol Sci. 1986;314(1165):1340. PubMed PMID: 22462104.

41. Shtonda BB, Avery L. Dietary choice behavior in Caenorhabditis elegans. J Exp Biol. 2006;209(Pt 1):89-102. doi: 10.1242/jeb.01955. PubMed PMID: 16354781; PubMed Central PMCID: PMCPMC1352325.

42. Bendesky A, Tsunozaki M, Rockman MV, Kruglyak L, Bargmann Cl. Catecholamine receptor polymorphisms affect decision-making in C. elegans. Nature. 2011;472(7343):313-8. 
821

822

823

824

825

826

827

828

829

830

831

832

833

834

835

836

837

838

839

840

841

842

843

844

845

846

847

848

849

850

851

852

853

854

855

856

857

858

859

860

861

862

863

864

865

866

867

868

869

870

doi: 10.1038/nature09821. PubMed PMID: 21412235; PubMed Central PMCID:

PMCPMC3154120.

43. Troemel ER, Kimmel BE, Bargmann Cl. Reprogramming chemotaxis responses:

sensory neurons define olfactory preferences in C. elegans. Cell. 1997;91(2):161-9. PubMed PMID: 9346234.

44. Ha HI, Hendricks M, Shen Y, Gabel CV, Fang-Yen C, Qin Y, et al. Functional organization of a neural network for aversive olfactory learning in Caenorhabditis elegans. Neuron. 2010;68(6):1173-86. doi: 10.1016/j.neuron.2010.11.025. PubMed PMID: 21172617; PubMed Central PMCID: PMCPMC3038580.

45. Tanimoto Y, Yamazoe-Umemoto A, Fujita K, Kawazoe Y, Miyanishi Y, Yamazaki SJ, et al. Calcium dynamics regulating the timing of decision-making in C. elegans. Elife. 2017;6. doi: 10.7554/eLife.21629. PubMed PMID: 28532547; PubMed Central PMCID: PMCPMC5441874. 46. Fetsch CR, DeAngelis GC, Angelaki DE. Bridging the gap between theories of sensory cue integration and the physiology of multisensory neurons. Nat Rev Neurosci. 2013;14(6):42942. doi: 10.1038/nrn3503. PubMed PMID: 23686172; PubMed Central PMCID: PMCPMC3820118.

47. Bianchi L, Gerstbrein B, Frokjaer-Jensen C, Royal DC, Mukherjee G, Royal MA, et al. The neurotoxic MEC-4(d) DEG/ENaC sodium channel conducts calcium: implications for necrosis initiation. Nat Neurosci. 2004;7(12):1337-44. doi: 10.1038/nn1347. PubMed PMID: 15543143.

48. Chalasani SH, Chronis N, Tsunozaki M, Gray JM, Ramot D, Goodman MB, et al. Dissecting a circuit for olfactory behaviour in Caenorhabditis elegans. Nature. 2007;450(7166):63-70. doi: 10.1038/nature06292. PubMed PMID: 17972877.

49. Milward K, Busch KE, Murphy RJ, de Bono M, Olofsson B. Neuronal and molecular substrates for optimal foraging in Caenorhabditis elegans. Proc Natl Acad Sci U S A. 2011;108(51):20672-7. doi: 10.1073/pnas.1106134109. PubMed PMID: 22135454; PubMed Central PMCID: PMCPMC3251049.

50. Calhoun AJ, Tong A, Pokala N, Fitzpatrick JA, Sharpee TO, Chalasani SH. Neural Mechanisms for Evaluating Environmental Variability in Caenorhabditis elegans. Neuron. 2015;86(2):428-41. doi: 10.1016/j.neuron.2015.03.026. PubMed PMID: 25864633; PubMed Central PMCID: PMCPMC4409562.

51. Zaslaver A, Liani I, Shtangel O, Ginzburg S, Yee L, Sternberg PW. Hierarchical sparse coding in the sensory system of Caenorhabditis elegans. Proc Natl Acad Sci U S A. 2015;112(4):1185-9. doi: 10.1073/pnas.1423656112. PubMed PMID: 25583501; PubMed Central PMCID: PMCPMC4313814.

52. Sengupta $\mathrm{P}$, Colbert HA, Bargmann Cl. The C. elegans gene odr-7 encodes an olfactory-specific member of the nuclear receptor superfamily. Cell. 1994;79(6):971-80. PubMed PMID: 8001144.

53. Uchida $\mathrm{O}$, Nakano $\mathrm{H}$, Koga $\mathrm{M}$, Ohshima $\mathrm{Y}$. The $\mathrm{C}$. elegans che-1 gene encodes a zinc finger transcription factor required for specification of the ASE chemosensory neurons. Development. 2003;130(7):1215-24. PubMed PMID: 12588839.

54. Conradt B, Horvitz HR. The TRA-1A sex determination protein of $C$. elegans regulates sexually dimorphic cell deaths by repressing the egl-1 cell death activator gene. Cell. 1999;98(3):317-27. PubMed PMID: 10458607.

55. Chang AJ, Chronis N, Karow DS, Marletta MA, Bargmann Cl. A distributed chemosensory circuit for oxygen preference in C. elegans. PLoS Biol. 2006;4(9):e274. doi: 10.1371/journal.pbio.0040274. PubMed PMID: 16903785; PubMed Central PMCID: PMCPMC1540710.

56. Zimmer M, Gray JM, Pokala N, Chang AJ, Karow DS, Marletta MA, et al. Neurons detect increases and decreases in oxygen levels using distinct guanylate cyclases. Neuron. 
871

872

873

874

875

876

877

878

879

880

881

882

883

884

885

886

887

888

889

890

891

892

893

894

895

896

897

898

899

900

901

902

903

904

905

906

907

908

909

910

911

912

913

914

915

916

917

918

919

920

921

2009;61(6):865-79. doi: 10.1016/j.neuron.2009.02.013. PubMed PMID: 19323996; PubMed Central PMCID: PMCPMC2760494.

57. Hallem EA, Spencer WC, McWhirter RD, Zeller G, Henz SR, Ratsch G, et al. Receptortype guanylate cyclase is required for carbon dioxide sensation by Caenorhabditis elegans. Proc Natl Acad Sci U S A. 2011;108(1):254-9. doi: 10.1073/pnas.1017354108. PubMed PMID: 21173231; PubMed Central PMCID: PMCPMC3017194.

58. Kunkel MT, Johnstone DB, Thomas JH, Salkoff L. Mutants of a temperature-sensitive two-P domain potassium channel. J Neurosci. 2000;20(20):7517-24. PubMed PMID: 11027209. 59. Schiavo G, Benfenati F, Poulain B, Rossetto O, Polverino de Laureto P, DasGupta BR, et al. Tetanus and botulinum-B neurotoxins block neurotransmitter release by proteolytic cleavage of synaptobrevin. Nature. 1992;359(6398):832-5. doi: 10.1038/359832a0. PubMed PMID: 1331807.

60. Beverly M, Anbil S, Sengupta P. Degeneracy and neuromodulation among thermosensory neurons contribute to robust thermosensory behaviors in Caenorhabditis elegans. J Neurosci. 2011;31(32):11718-27. doi: 10.1523/JNEUROSCI.1098-11.2011. PubMed PMID: 21832201; PubMed Central PMCID: PMCPMC3167209.

61. Srinivasan J, von Reuss SH, Bose N, Zaslaver A, Mahanti P, Ho MC, et al. A modular library of small molecule signals regulates social behaviors in Caenorhabditis elegans. PLoS Biol. 2012;10(1):e1001237. doi: 10.1371/journal.pbio.1001237. PubMed PMID: 22253572; PubMed Central PMCID: PMCPMC3254649.

62. Cornils A, Gloeck M, Chen Z, Zhang Y, Alcedo J. Specific insulin-like peptides encode sensory information to regulate distinct developmental processes. Development. 2011;138(6):1183-93. doi: 10.1242/dev.060905. PubMed PMID: 21343369; PubMed Central PMCID: PMCPMC3042873.

63. Macosko EZ, Pokala N, Feinberg EH, Chalasani SH, Butcher RA, Clardy J, et al. A huband-spoke circuit drives pheromone attraction and social behaviour in $\mathrm{C}$. elegans. Nature. 2009;458(7242):1171-5. doi: 10.1038/nature07886. PubMed PMID: 19349961; PubMed Central PMCID: PMCPMC2760495.

64. Jang H, Kim K, Neal SJ, Macosko E, Kim D, Butcher RA, et al. Neuromodulatory state and sex specify alternative behaviors through antagonistic synaptic pathways in C. elegans. Neuron. 2012;75(4):585-92. doi: 10.1016/j.neuron.2012.06.034. PubMed PMID: 22920251; PubMed Central PMCID: PMCPMC3462069.

65. Sze JY, Victor M, Loer C, Shi Y, Ruvkun G. Food and metabolic signalling defects in a Caenorhabditis elegans serotonin-synthesis mutant. Nature. 2000;403(6769):560-4. doi: 10.1038/35000609. PubMed PMID: 10676966.

66. Calvo AC, Pey AL, Miranda-Vizuete A, Doskeland AP, Martinez A. Divergence in enzyme regulation between Caenorhabditis elegans and human tyrosine hydroxylase, the key enzyme in the synthesis of dopamine. Biochem J. 2011;434(1):133-41. doi: 10.1042/BJ20101561. PubMed PMID: 21087208.

67. Alkema MJ, Hunter-Ensor M, Ringstad N, Horvitz HR. Tyramine Functions independently of octopamine in the Caenorhabditis elegans nervous system. Neuron. 2005;46(2):247-60. doi: 10.1016/j.neuron.2005.02.024. PubMed PMID: 15848803. 68. Kass J, Jacob TC, Kim P, Kaplan JM. The EGL-3 proprotein convertase regulates mechanosensory responses of Caenorhabditis elegans. J Neurosci. 2001;21(23):9265-72. PubMed PMID: 11717360.

69. Thacker C, Srayko M, Rose AM. Mutational analysis of bli-4/kpc-4 reveals critical residues required for proprotein convertase function in C. elegans. Gene. 2000;252(1-2):15-25. PubMed PMID: 10903434.

70. Thacker C, Rose AM. A look at the Caenorhabditis elegans Kex2/Subtilisin-like proprotein convertase family. Bioessays. 2000;22(6):545-53. doi: 10.1002/(SICI)15211878(200006)22:6<545::AID-BIES7>3.0.CO;2-F. PubMed PMID: 10842308. 
922

923

924

925

926

927

928

929

930

931

932

933

934

935

936

937

938

939

940

941

942

943

944

945

946

947

948

949

950

951

952

953

954

955

956

957

958

959

960

961

962

963

964

965

966

967

968

969

970

971

71. Meisel JD, Panda O, Mahanti P, Schroeder FC, Kim DH. Chemosensation of bacterial secondary metabolites modulates neuroendocrine signaling and behavior of $C$. elegans. Cell. 2014;159(2):267-80. doi: 10.1016/j.cell.2014.09.011. PubMed PMID: 25303524; PubMed Central PMCID: PMCPMC4194030.

72. Ren P, Lim CS, Johnsen R, Albert PS, Pilgrim D, Riddle DL. Control of C. elegans larval development by neuronal expression of a TGF-beta homolog. Science. 1996;274(5291):138991. PubMed PMID: 8910282.

73. Greer ER, Perez CL, Van Gilst MR, Lee BH, Ashrafi K. Neural and molecular dissection of a C. elegans sensory circuit that regulates fat and feeding. Cell Metab. 2008;8(2):118-31. doi: 10.1016/j.cmet.2008.06.005. PubMed PMID: 18680713; PubMed Central PMCID: PMCPMC2556218.

74. Park SK, Tedesco PM, Johnson TE. Oxidative stress and longevity in Caenorhabditis elegans as mediated by SKN-1. Aging Cell. 2009;8(3):258-69. doi: 10.1111/j.14749726.2009.00473.x. PubMed PMID: 19627265; PubMed Central PMCID: PMCPMC2762118. 75. Park SK, Link CD, Johnson TE. Life-span extension by dietary restriction is mediated by NLP-7 signaling and coelomocyte endocytosis in C. elegans. FASEB J. 2010;24(2):383-92. doi: 10.1096/fj.09-142984. PubMed PMID: 19783783; PubMed Central PMCID: PMCPMC2812037. 76. Banerjee N, Bhattacharya R, Gorczyca M, Collins KM, Francis MM. Local neuropeptide signaling modulates serotonergic transmission to shape the temporal organization of $\mathrm{C}$. elegans egg-laying behavior. PLoS Genet. 2017;13(4):e1006697. doi: 10.1371/journal.pgen.1006697. PubMed PMID: 28384151; PubMed Central PMCID: PMCPMC5398689.

77. Mills H, Wragg R, Hapiak V, Castelletto M, Zahratka J, Harris G, et al. Monoamines and neuropeptides interact to inhibit aversive behaviour in Caenorhabditis elegans. EMBO J. 2012;31(3):667-78. doi: 10.1038/emboj.2011.422. PubMed PMID: 22124329; PubMed Central PMCID: PMCPMC3273394.

78. Georgi LL, Albert PS, Riddle DL. daf-1, a C. elegans gene controlling dauer larva development, encodes a novel receptor protein kinase. Cell. 1990;61(4):635-45. PubMed PMID: 2160853.

79. Estevez M, Attisano L, Wrana JL, Albert PS, Massague J, Riddle DL. The daf-4 gene encodes a bone morphogenetic protein receptor controlling $C$. elegans dauer larva development. Nature. 1993;365(6447):644-9. doi: 10.1038/365644a0. PubMed PMID: 8413626. 80. Diana G, Patel DS, Entchev EV, Zhan M, Lu H, Ch'ng Q. Genetic control of encoding strategy in a food-sensing neural circuit. Elife. 2017;6. doi: 10.7554/eLife.24040. PubMed PMID: 28166866; PubMed Central PMCID: PMCPMC5295820.

81. Entchev EV, Patel DS, Zhan M, Steele AJ, Lu H, Ch'ng Q. A gene-expression-based neural code for food abundance that modulates lifespan. Elife. 2015;4:e06259. doi:

10.7554/eLife.06259. PubMed PMID: 25962853; PubMed Central PMCID: PMCPMC4417936. 82. Gallagher T, Kim J, Oldenbroek M, Kerr R, You YJ. ASI regulates satiety quiescence in C. elegans. J Neurosci. 2013;33(23):9716-24. doi: 10.1523/JNEUROSCI.4493-12.2013. PubMed PMID: 23739968; PubMed Central PMCID: PMCPMC3726252.

83. Fletcher M, Kim DH. Age-Dependent Neuroendocrine Signaling from Sensory Neurons Modulates the Effect of Dietary Restriction on Longevity of Caenorhabditis elegans. PLoS Genet. 2017;13(1):e1006544. doi: 10.1371/journal.pgen.1006544. PubMed PMID: 28107363; PubMed Central PMCID: PMCPMC5291536.

84. Tobin DM, Madsen DM, Kahn-Kirby A, Peckol EL, Moulder G, Barstead R, et al. Combinatorial expression of TRPV channel proteins defines their sensory functions and subcellular localization in C. elegans neurons. Neuron. 2002;35(2):307-18. PubMed PMID: 12160748.

85. Upadhyay A, Pisupati A, Jegla T, Crook M, Mickolajczyk KJ, Shorey M, et al. Nicotinamide is an endogenous agonist for a C. elegans TRPV OSM-9 and OCR-4 channel. Nat 
972

973

974

975

976

977

978

979

980

981

982

983

984

985

986

987

988

989

990

991

992

993

994

995

996

997

998

999

1000

1001

1002

1003

1004

1005

1006

1007

1008

1009

1010

1011

1012

1013

1014

1015

1016

1017

1018

1019

1020

1021

Commun. 2016;7:13135. doi: 10.1038/ncomms13135. PubMed PMID: 27731314; PubMed Central PMCID: PMCPMC5064019.

86. Flames N, Hobert O. Gene regulatory logic of dopamine neuron differentiation. Nature. 2009;458(7240):885-9. doi: 10.1038/nature07929. PubMed PMID: 19287374; PubMed Central PMCID: PMCPMC2671564.

87. Gordus A, Pokala N, Levy S, Flavell SW, Bargmann Cl. Feedback from network states generates variability in a probabilistic olfactory circuit. Cell. 2015;161(2):215-27. doi: 10.1016/j.cell.2015.02.018. PubMed PMID: 25772698; PubMed Central PMCID: PMCPMC4821011.

88. Tsalik EL, Hobert O. Functional mapping of neurons that control locomotory behavior in Caenorhabditis elegans. J Neurobiol. 2003;56(2):178-97. doi: 10.1002/neu.10245. PubMed PMID: 12838583.

89. Hobert O, Mori I, Yamashita Y, Honda H, Ohshima Y, Liu Y, et al. Regulation of interneuron function in the $\mathrm{C}$. elegans thermoregulatory pathway by the ttx-3 LIM homeobox gene. Neuron. 1997;19(2):345-57. PubMed PMID: 9292724.

90. Brockie PJ, Madsen DM, Zheng Y, Mellem J, Maricq AV. Differential expression of glutamate receptor subunits in the nervous system of Caenorhabditis elegans and their regulation by the homeodomain protein UNC-42. J Neurosci. 2001;21(5):1510-22. PubMed PMID: 11222641.

91. Leinwand SG, Yang CJ, Bazopoulou D, Chronis N, Srinivasan J, Chalasani SH. Circuit mechanisms encoding odors and driving aging-associated behavioral declines in Caenorhabditis elegans. Elife. 2015;4:e10181. doi: 10.7554/eLife.10181. PubMed PMID: 26394000; PubMed Central PMCID: PMCPMC4577979.

92. Troemel ER, Chou JH, Dwyer ND, Colbert HA, Bargmann Cl. Divergent seven transmembrane receptors are candidate chemosensory receptors in C. elegans. Cell. 1995;83(2):207-18. PubMed PMID: 7585938.

93. Luo L, Gabel CV, Ha HI, Zhang Y, Samuel AD. Olfactory behavior of swimming C. elegans analyzed by measuring motile responses to temporal variations of odorants. J Neurophysiol. 2008;99(5):2617-25. doi: 10.1152/jn.00053.2008. PubMed PMID: 18367700. 94. Olofsson B. The olfactory neuron AWC promotes avoidance of normally palatable food following chronic dietary restriction. J Exp Biol. 2014;217(Pt 10):1790-8. doi:

10.1242/jeb.099929. PubMed PMID: 24577446; PubMed Central PMCID: PMCPMC4020945. 95. Wakabayashi T, Kimura Y, Ohba Y, Adachi R, Satoh Y, Shingai R. In vivo calcium imaging of OFF-responding ASK chemosensory neurons in C. elegans. Biochim Biophys Acta. 2009;1790(8):765-9. doi: 10.1016/j.bbagen.2009.03.032. PubMed PMID: 19362117.

96. Chen Z, Hendricks M, Cornils A, Maier W, Alcedo J, Zhang Y. Two insulin-like peptides antagonistically regulate aversive olfactory learning in C. elegans. Neuron. 2013;77(3):572-85. doi: 10.1016/j.neuron.2012.11.025. PubMed PMID: 23395381; PubMed Central PMCID: PMCPMC3569836.

97. Chalasani SH, Kato S, Albrecht DR, Nakagawa T, Abbott LF, Bargmann Cl. Neuropeptide feedback modifies odor-evoked dynamics in Caenorhabditis elegans olfactory neurons. Nat Neurosci. 2010;13(5):615-21. doi: 10.1038/nn.2526. PubMed PMID: 20364145; PubMed Central PMCID: PMCPMC2937567.

98. Cohen M, Reale V, Olofsson B, Knights A, Evans P, de Bono M. Coordinated regulation of foraging and metabolism in $\mathrm{C}$. elegans by RFamide neuropeptide signaling. Cell Metab. 2009;9(4):375-85. doi: 10.1016/j.cmet.2009.02.003. PubMed PMID: 19356718.

99. Harris G, Shen Y, Ha H, Donato A, Wallis S, Zhang X, et al. Dissecting the signaling mechanisms underlying recognition and preference of food odors. J Neurosci.

2014;34(28):9389-403. doi: 10.1523/JNEUROSCI.0012-14.2014. PubMed PMID: 25009271; PubMed Central PMCID: PMCPMC4087214. 
1022

1023

1024

1025

1026

1027

1028

1029

1030

1031

1032

1033

1034

1035

1036

1037

1038

1039

1040

1041

1042

1043

1044

1045

1046

1047

1048

1049

1050

1051

1052

1053

1054

1055

1056

1057

1058

1059

1060

1061

1062

1063

1064

1065

1066

1067

1068

1069

1070

1071

100. Hapiak V, Summers P, Ortega A, Law WJ, Stein A, Komuniecki R. Neuropeptides amplify and focus the monoaminergic inhibition of nociception in Caenorhabditis elegans. J Neurosci. 2013;33(35):14107-16. doi: 10.1523/JNEUROSCI.1324-13.2013. PubMed PMID: 23986246; PubMed Central PMCID: PMCPMC3756756.

101. Sulston J, Dew M, Brenner S. Dopaminergic neurons in the nematode Caenorhabditis elegans. J Comp Neurol. 1975;163(2):215-26. doi: 10.1002/cne.901630207. PubMed PMID: 240872.

102. Chatzigeorgiou M, Schafer WR. Lateral facilitation between primary mechanosensory neurons controls nose touch perception in C. elegans. Neuron. 2011;70(2):299-309. doi: 10.1016/j.neuron.2011.02.046. PubMed PMID: 21521615; PubMed Central PMCID: PMCPMC3145979.

103. Harris G, Korchnak A, Summers P, Hapiak V, Law WJ, Stein AM, et al. Dissecting the serotonergic food signal stimulating sensory-mediated aversive behavior in C. elegans. PLoS One. 2011;6(7):e21897. doi: 10.1371/journal.pone.0021897. PubMed PMID: 21814562;

PubMed Central PMCID: PMCPMC3140990.

104. Ageta $\mathrm{H}$, Ikegami S, Miura M, Masuda M, Migishima R, Hino T, et al. Activin plays a key role in the maintenance of long-term memory and late-LTP. Learn Mem. 2010;17(4):176-85. doi: 10.1101/Im.16659010. PubMed PMID: 20332189.

105. Goold CP, Davis GW. The BMP ligand Gbb gates the expression of synaptic homeostasis independent of synaptic growth control. Neuron. 2007;56(1):109-23. doi: 10.1016/j.neuron.2007.08.006. PubMed PMID: 17920019; PubMed Central PMCID: PMCPMC2699048.

106. Sun M, Thomas MJ, Herder R, Bofenkamp ML, Selleck SB, O'Connor MB. Presynaptic contributions of chordin to hippocampal plasticity and spatial learning. J Neurosci. 2007;27(29):7740-50. doi: 10.1523/JNEUROSCI.1604-07.2007. PubMed PMID: 17634368. 107. Zhang F, Endo S, Cleary LJ, Eskin A, Byrne JH. Role of transforming growth factor-beta in long-term synaptic facilitation in Aplysia. Science. 1997;275(5304):1318-20. PubMed PMID: 9036859.

108. Tesseur I, Zou K, Esposito L, Bard F, Berber E, Can JV, et al. Deficiency in neuronal TGF-beta signaling promotes neurodegeneration and Alzheimer's pathology. J Clin Invest. 2006;116(11):3060-9. doi: 10.1172/JCI27341. PubMed PMID: 17080199; PubMed Central PMCID: PMCPMC1626127.

109. Ueberham U, Ueberham E, Gruschka H, Arendt T. Altered subcellular location of phosphorylated Smads in Alzheimer's disease. Eur J Neurosci. 2006;24(8):2327-34. doi: 10.1111/j.1460-9568.2006.05109.x. PubMed PMID: 17074053.

110. Benes FM, Lim B, Matzilevich D, Walsh JP, Subburaju S, Minns M. Regulation of the GABA cell phenotype in hippocampus of schizophrenics and bipolars. Proc Natl Acad Sci U S A. 2007;104(24):10164-9. doi: 10.1073/pnas.0703806104. PubMed PMID: 17553960; PubMed Central PMCID: PMCPMC1888575.

111. Stanford TR, Quessy S, Stein BE. Evaluating the operations underlying multisensory integration in the cat superior colliculus. J Neurosci. 2005;25(28):6499-508. doi:

10.1523/JNEUROSCI.5095-04.2005. PubMed PMID: 16014711; PubMed Central PMCID: PMCPMC1237124.

112. Harris GP, Hapiak VM, Wragg RT, Miller SB, Hughes LJ, Hobson RJ, et al. Three distinct amine receptors operating at different levels within the locomotory circuit are each essential for the serotonergic modulation of chemosensation in Caenorhabditis elegans. $J$ Neurosci. 2009;29(5):1446-56. doi: 10.1523/JNEUROSCI.4585-08.2009. PubMed PMID: 19193891; PubMed Central PMCID: PMCPMC3418693.

113. Luo L, Wen Q, Ren J, Hendricks M, Gershow M, Qin Y, et al. Dynamic encoding of perception, memory, and movement in a C. elegans chemotaxis circuit. Neuron. 
1072

1073

1074

1075

1076

1077

1078

1079

1080

1081

1082

1083

1084

1085

1086

1087

1088

1089

1090

1091

1092

1093

1094

1095

1096

1097

1098

1099

1100

1101

1102

2014;82(5):1115-28. doi: 10.1016/j.neuron.2014.05.010. PubMed PMID: 24908490; PubMed Central PMCID: PMCPMC4082684.

114. Ishihara T, lino Y, Mohri A, Mori I, Gengyo-Ando K, Mitani S, et al. HEN-1, a secretory protein with an LDL receptor motif, regulates sensory integration and learning in Caenorhabditis elegans. Cell. 2002;109(5):639-49. PubMed PMID: 12062106.

115. Yoshida K, Hirotsu T, Tagawa T, Oda S, Wakabayashi T, lino Y, et al. Odour concentration-dependent olfactory preference change in C. elegans. Nat Commun. 2012;3:739. doi: 10.1038/ncomms1750. PubMed PMID: 22415830.

116. Brenner S. The genetics of Caenorhabditis elegans. Genetics. 1974;77(1):71-94. Epub 1974/05/01. PubMed PMID: 4366476; PubMed Central PMCID: PMCPMC1213120.

117. Mello CC, Kramer JM, Stinchcomb D, Ambros V. Efficient gene transfer in C.elegans: extrachromosomal maintenance and integration of transforming sequences. EMBO J.

1991;10(12):3959-70. PubMed PMID: 1935914; PubMed Central PMCID: PMCPMC453137.

\section{Supporting information}

\section{S1 Table. 2-nonanone avoidance assay.}

Wild type, mutants and transgenic animals are examined for avoiding $100 \%$ 2-nonanone as previously described (Troemel et al., 1997 and S5 Figure). Avoidance Index was calculated as described in S5 Figure. The avoidance in each genotype is represented by the average avoidance index of individual assays. $n=2-4$ assays each genotype, 75-100 animals tested in each assay, mutants and transgenic animals are compared with wild-type animals or the nontransgenic siblings tested on the same days with student's $t$ test, Mean \pm SEM.

\section{S2 Table. Time to reach the edge of the food lawn during multisensory integration}

Wild type, mutants and transgenic animals are examined for the time taken to reach the edge of the food lawn away from the repellent. The average time taken for $90 \%$ of the worms in one assay to reach the edge of a E. coli OP50 food lawns during exposure to $100 \%$ 2-nonanone is presented for each genotype (Experimental Procedures). $n=2-4$ assays for each genotype, 20-25 animals tested in each assay, mutants or transgenic animals are compared with wild-type animals or non-transgenic siblings tested on the same days with student's $t$ test, Mean \pm SEM. 
1104 Wild type, mutant animals and transgenic animals are examined for food leaving for 1 hour.

1105 Young adult worms are placed on an OP50 food lawn for 1 hour and the number of worms on

1106 food lawn is counted every 5 minutes for a total assay time of 60 minutes. The percentage of

1107 worms off the food lawn at 15 minutes is reported. $n=2-4$ assays for each genotype and 20-

110825 worms in each assay, mutants or transgenic animals are compared with wild-type animals

1109 tested in parallel with student's $t$ test, Mean \pm SEM.

1111 S4 Table. Many signaling mutants show no phenotype in 2-nonanone-dependent food

1112 leaving. Wild type, mutant and transgenic animals are examined for leaving an E. coli OP50

1113 food lawn paired with 100\% 2-nonanone. The average percentage of worms outside the food

1114 lawn at 15 minutes is reported. Mutants or transgenic animals are compared with the wild-type

1115 control tested on the same days with student's $t$ test, $n=2-4$ assays for each genotype, 20-25

1116 animals in each assay, Mean \pm SEM.

1117

\section{S5 Fig. Schematics of assays}

1119 (A) Assay to measure time taken to reach the edge of the food lawn (Experimental Procedures).

1120 (B) Chemotaxis assay for avoidance of $100 \%$ 2-nonanone (Experimental Procedures)

1122 S6 Fig. Additional alleles of $t d c-1$ and $t b h-1$ mutants are also wild-type for 2-nonanone-

\section{3 dependent food leaving.}

1124 Each bar graph shows the percentage of animals outside the food lawn 15 minutes after the 1125 start of the assay, mutants are compared with wild type tested in parallel with Student's $t$ test, $1126 \mathrm{n}=3$ assays each; mean \pm SEM, n.s., not significant. 
1128 S7 Fig. DAF-7 produced by the sensory neurons ASI does not regulate 2-nonanone-

1129 dependent food leaving.

1130 Expressing a wild-type daf-7 cDNA in the sensory neurons ASI does not rescue the delayed

1131 decision phenotype in the daf-7(e1372) mutant animals ( $n=4,3$ and 4 assays for wild type,

1132 transgenic animals and non-transgenic siblings, respectively).

1133 Each bar graph shows the average percentage of worms outside the lawn 15 minutes after the

1134 start of the assay, transgenic animals are compared with non-transgenic siblings using

1135 Student's t-test, n.s., not significant.

1136

1137 S8 Fig. Expressing the daf-1 cDNA in sensory neurons with osm-6 promoter does not

1138 rescue the delayed-decision phenotype in the daf-1(m40) mutants. The transgenic animals

1139 ( $n=3$ assays) are compared with non-transgenic siblings ( $n=4$ assays) with Student's $t$ test,

1140 wild type $=3$ assays; bar graph shows the percentage of worms outside of lawn 15 minutes

1141 after the start of the assay, mean \pm SEM, n.s., not significant.

1142

1143 S9 Movie. Wild-type worms performing food leaving on an E. coli OP50 lawn paired with

$1144 \quad 100 \%$ 2-nonanone.

1145

1146 S10 Movie. Wild-type worms performing food leaving on an E. coli OP50 food lawn paired

1147 with $100 \%$ benzaldehyde. 

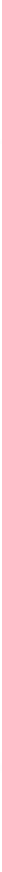

D

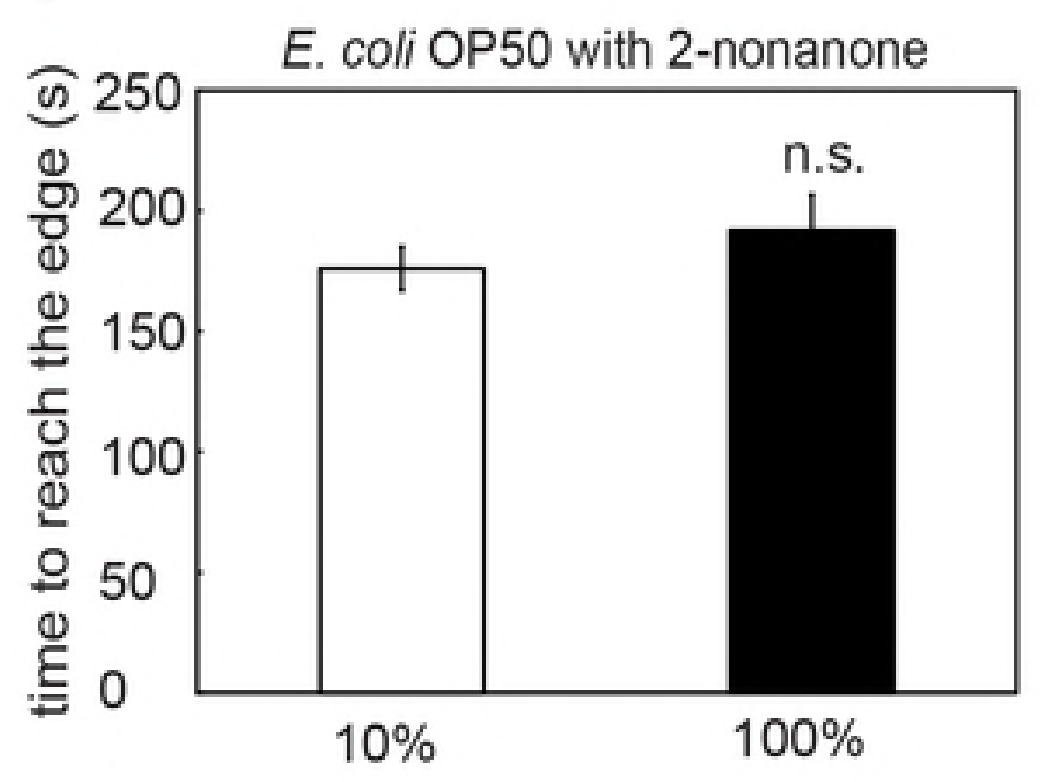

E I) at 2 minute

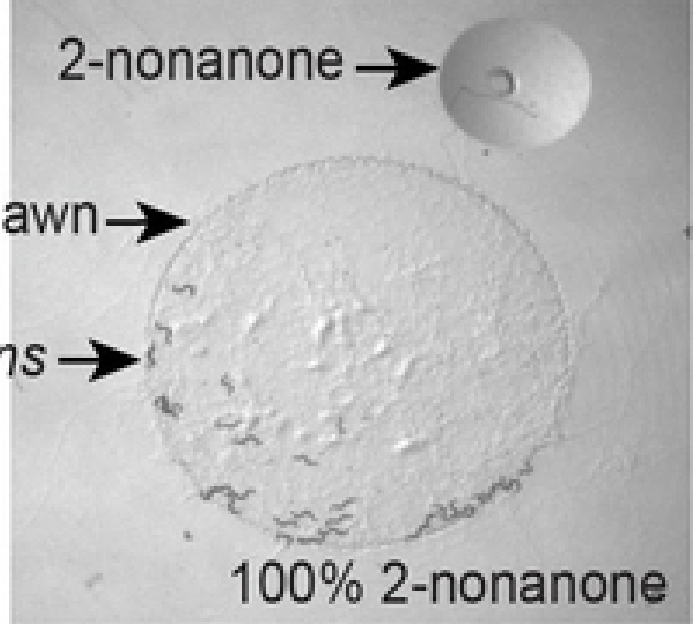

III) at 10 minute
II) at 5 minute

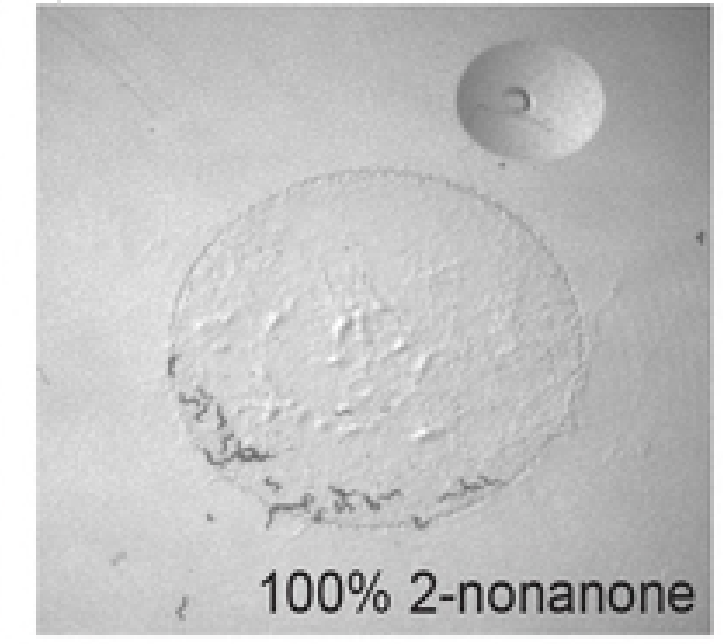

IV) at 15 minute 

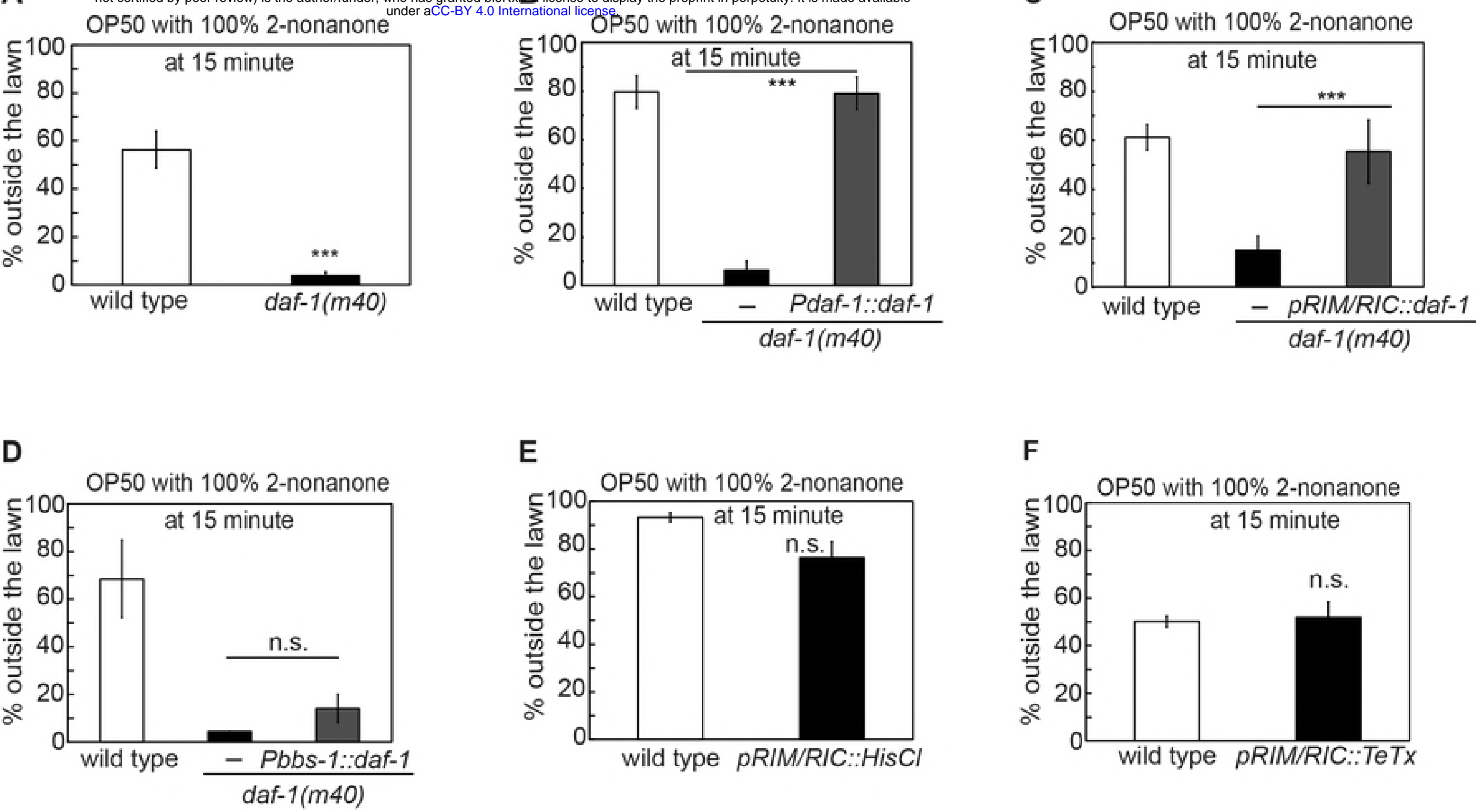

\section{E}

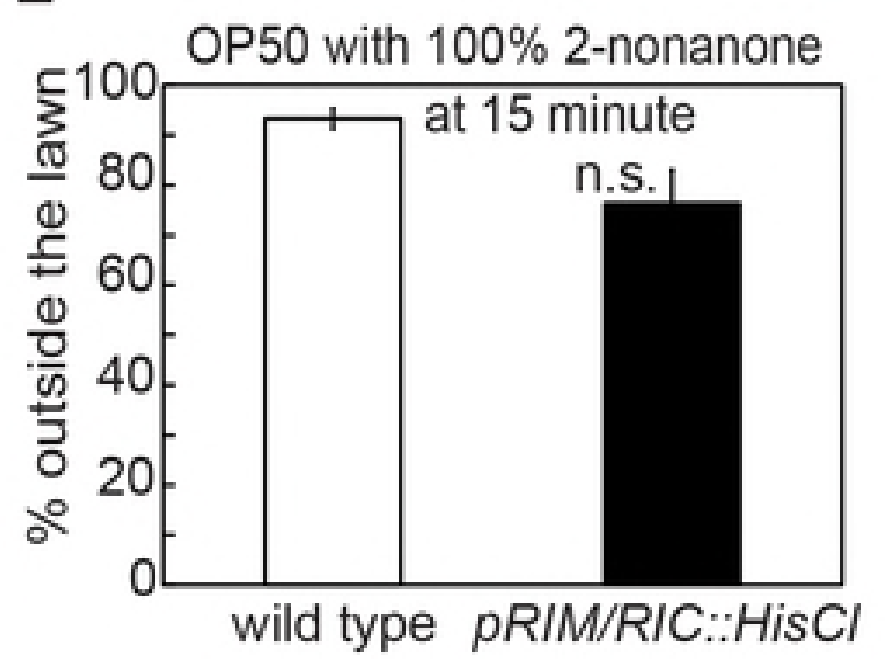

H

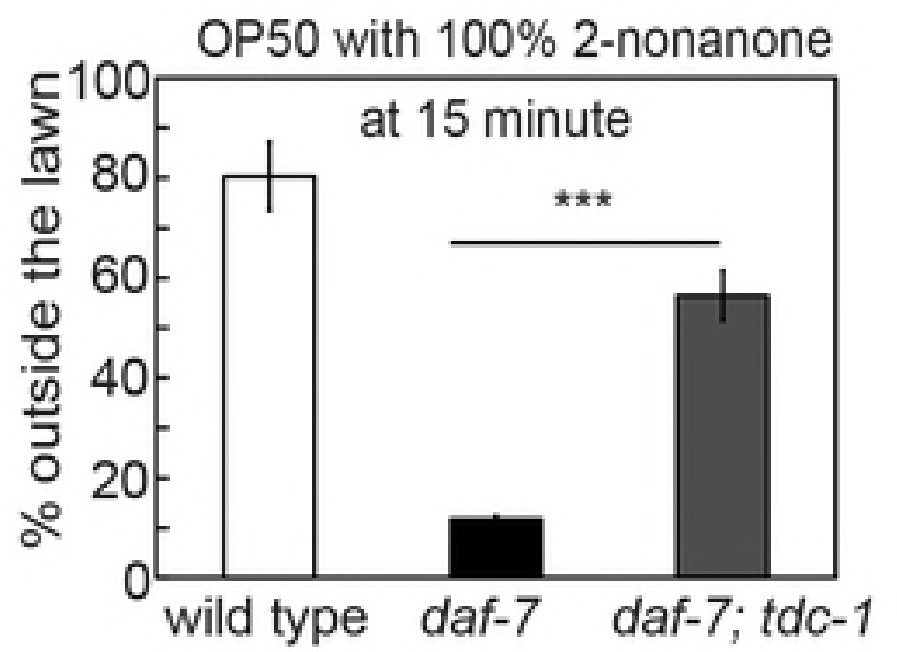

F

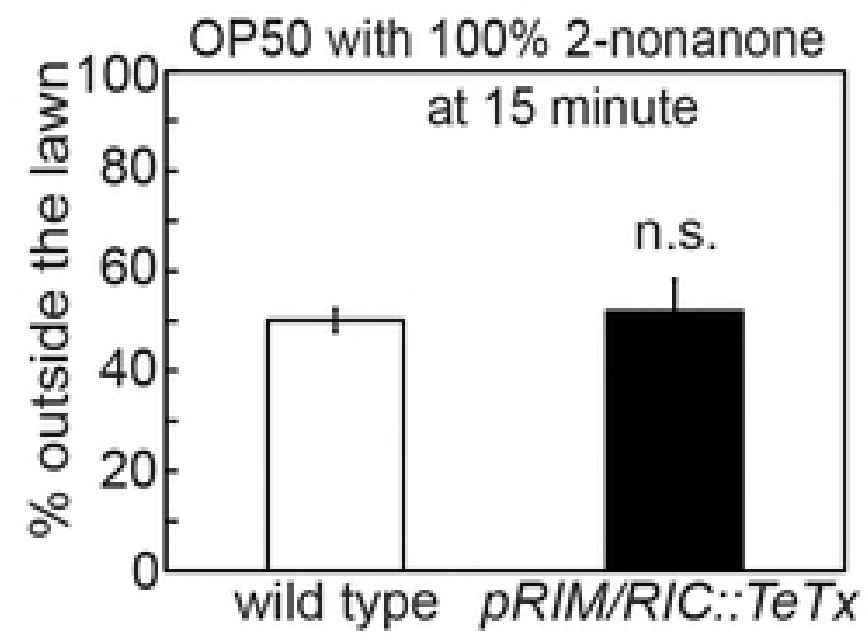

I

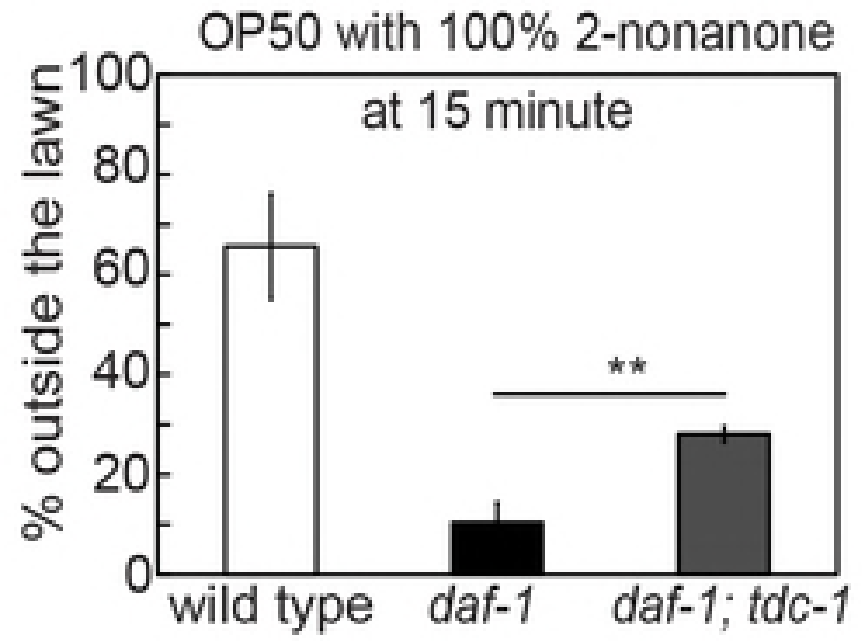

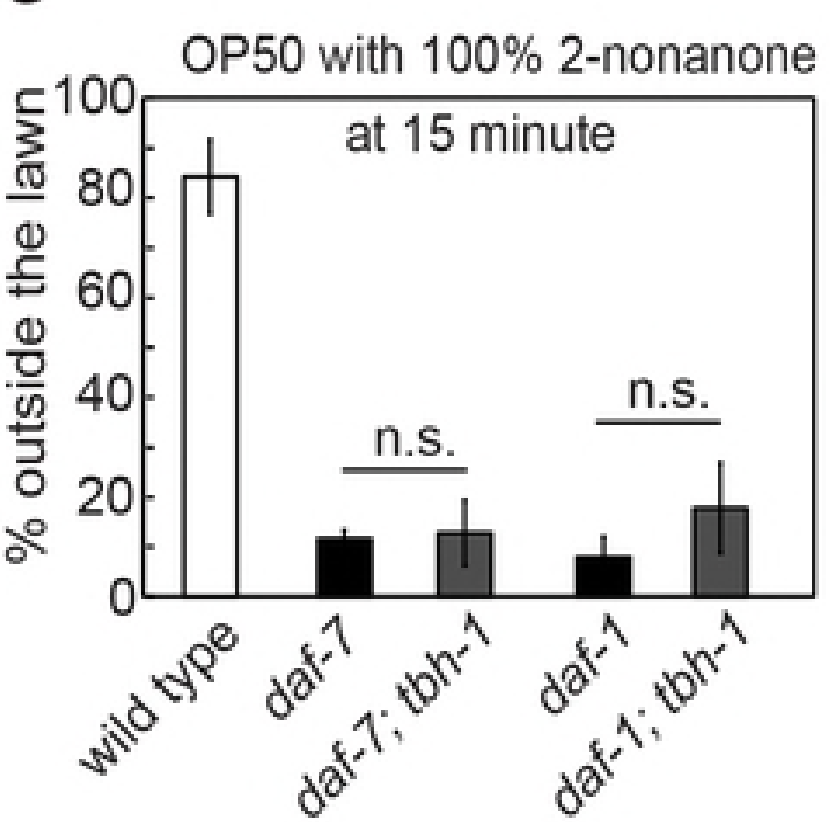




\section{A}

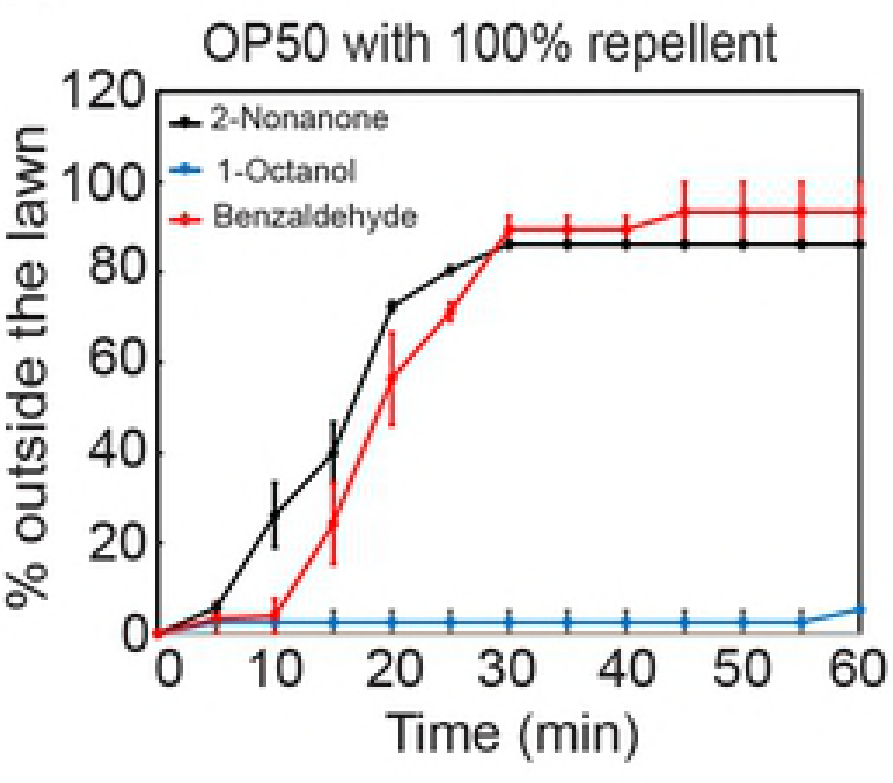

D

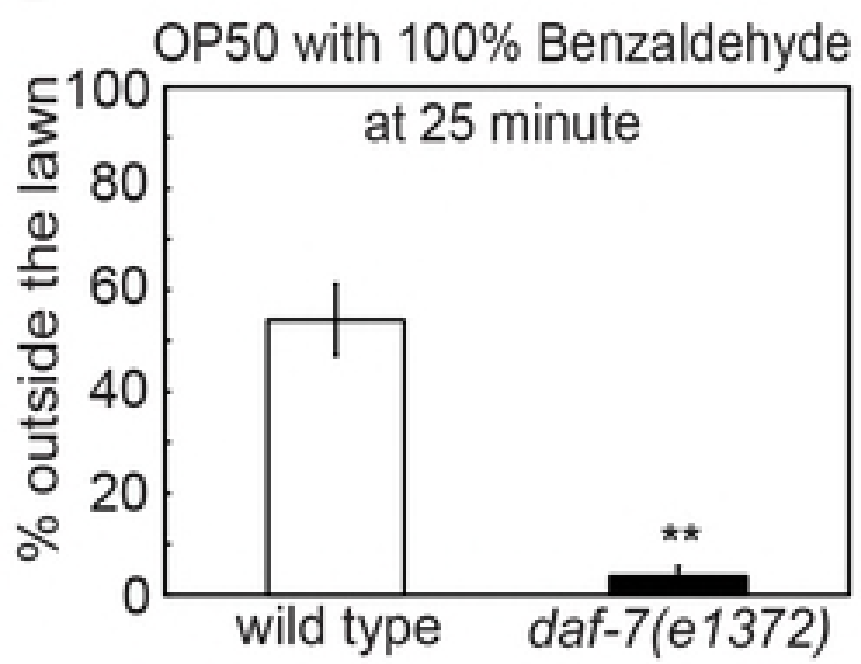

B

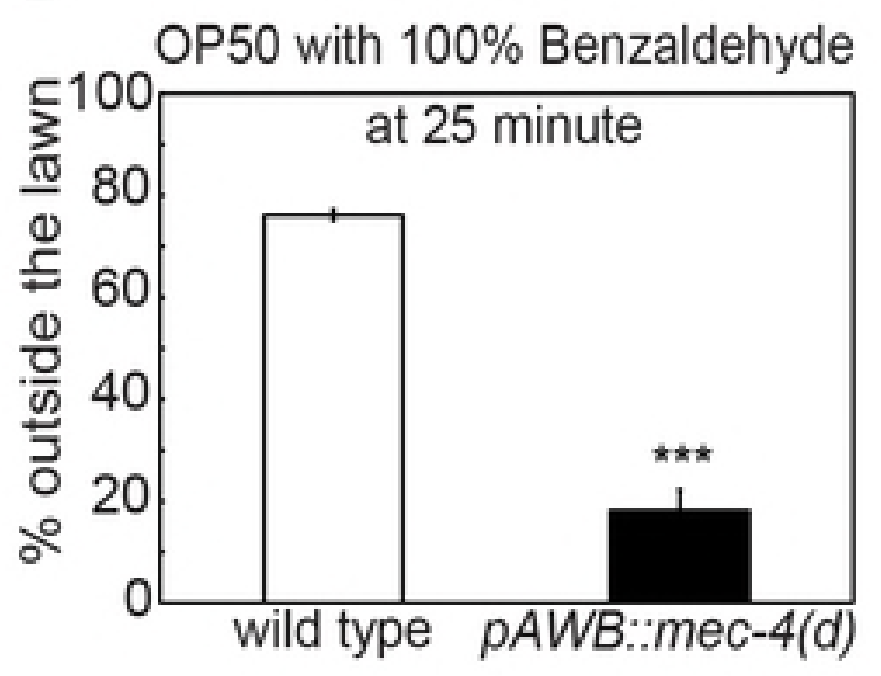

C

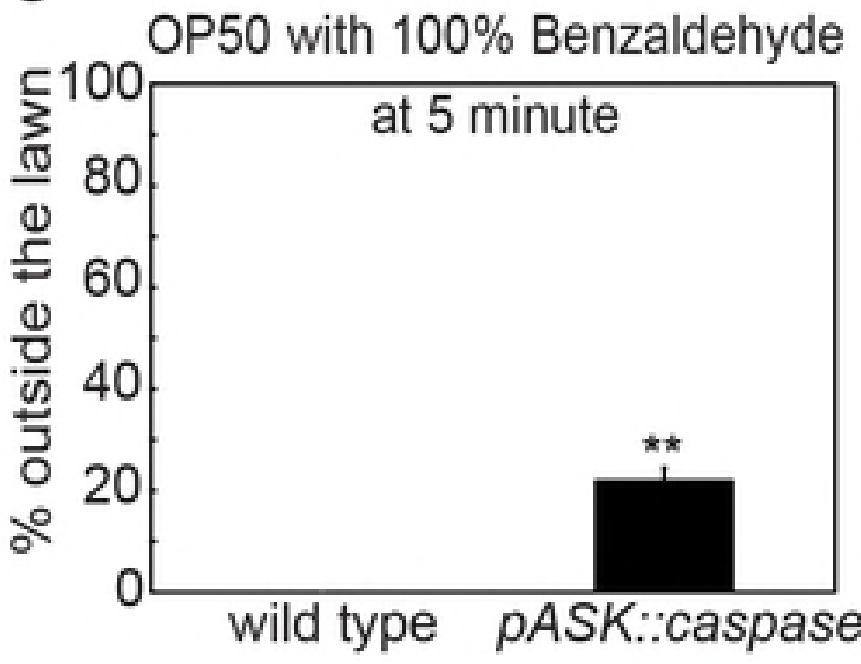

E

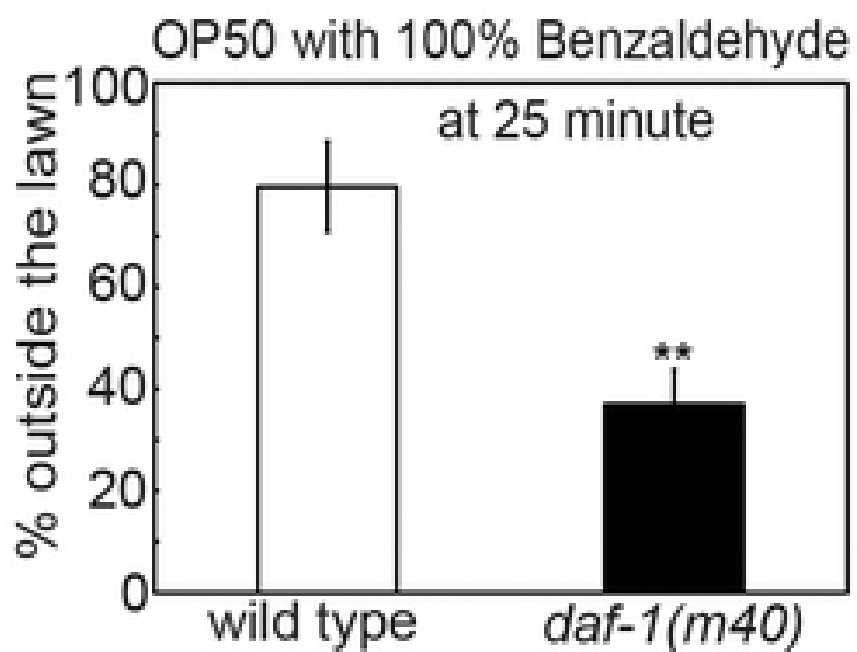


